\title{
Explaining Morphosyntactic Competition
}

\author{
JOAN BRESNAN
}

Final revision of February 18, $1999^{1}$

Morphosyntactic markedness theory classically assumes dynamic competition among the members of a paradigm. They are in opposition within a system of contrasts, and their meaning, or use, is determined by their relation to each other in the paradigm, not by their intrinsic features alone. This idea is embodied in Jakobson's (1984: 1) often-cited formulation of morphosyntactic unmarkedness in his work on the structure of the Russian verb:

When a linguist investigates two morphological categories in mutual opposition, he often starts from the assumption that both categories should be of equal value, and that each of them should possess a positive meaning of its own: Category I should signify A, while Category II should signify B; or at least I should signify $\mathrm{A}$, and II the absence or negation of A. In reality, the general meanings of correlative categories are distributed in a different way: If Category I announces the existence of A, then Category II does not announce the existence of $\mathrm{A}$, i.e. it does not state whether $\mathrm{A}$ is present or not. The general meaning of the unmarked Category II, as compared to the marked Category I, is restricted to the lack of "A-signalization".

Jakobson gives (1) as a simple example:

(1) Russian: oslica 'she-ass', osël 'donkey' èto oslíca? 'Is it a she-ass?' — nét, osël 'no, a donkey'.

\footnotetext{
${ }^{1}$ To appear in Handbook of Contemporary Syntactic Theory, ed. by Mark Baltin and Chris Collins. Oxford: Blackwell. I am grateful to Avery Andrews, Mark Baltin, Jim Blevins, Andrew Bredenkamp, Chris Collins, Edward Flemming, Jane Grimshaw, Dick Hudson, Mark Johnson, Knud Lambrecht, Andrew Carstairs-McCarthy, Scott Myers, Alan Prince, Geoff Pullum, Peter Sells, Petr Sgall, Paul Smolensky, Ida Toivonen, David Wilkins, Mary McGee Wood, and Nigel Vincent for critical suggestions, though I am solely responsible for the use made of their comments.
} 
Here a Russian feminine gender noun oslíca 'she-ass' is the marked category used only for a female animal of the species, where the corresponding masculine gender noun osël 'donkey' is used for animals of both sexes. However, in a specific context of contrast the female meaning may be cancelled, leaving only the male meaning: èto oslíca? 'Is it a she-ass?' —nét, osël 'no, a donkey'. Thus, depending on context, the unmarked (neutral) form can be used either inclusively, subsuming the marked, or exclusively, in opposition to the marked. This general idea that "the unmarked member acts as a surrogate for the entire category" (Greenberg, 1966: 61) is widely instantiated in phonology, in morphology, and in morphosyntactic systems such as case, agreement, and voice, as well as in other syntactic, semantic and pragmatic domains.

If we represent Jakobson's 'marked' as in (2) by a feature specification such as $[\mathrm{FEM}]$ for the feminine gender variant, then the 'unmarked' is the neutral form, lacking any specification such as [MASC] or $\neg[\mathrm{FEM}]$.

$$
\begin{array}{ll}
\text { (2) marked: } & {[\mathrm{FEM}]} \\
& \text { unmarked: }[]
\end{array}
$$

Observe that the specifications in $(3 a, b)$ fail to capture the inclusive use of the unmarked form by excluding the feminine gender:

(3) a. $[\mathrm{MASC}]$

$$
\begin{aligned}
& \text { b. } \neg[\mathrm{FEM}] \\
& \text { c. }[\mathrm{MASC}] \vee[\mathrm{FEM}]
\end{aligned}
$$

An inclusive meaning is represented in (3c) by stipulating a disjunction of features. But any disjunction of features could be stipulated in this way. What is not captured is that the meaning of a neutral form derives dynamically from its role within a paradigm: it may subsume or contrast with the meanings of the other elements in relation to it.

The representation of neutral forms as featurally unmarked raises wellknown problems for syntactic theory, however. Suppose, for example, that there is gender concord in a language that has a marked feminine gender as in (2). If concord between two elements is represented as checking for compatibility, or unification, of their feature structures, then the unmarked masculine form would wrongly be expected to be compatible with both feminine and masculine genders. To solve this problem, most feature-logic based syntactic 
theories (including LFG, categorial unification grammar, and HPSG) have resorted to overspecification of the unmarked form by adopting negations and disjunctions of features, as in (3) (Karttunen, 1984; Pollard and Sag, 1987; Maxwell and Kaplan, 1995). ${ }^{2}$

\section{Markedness in Blocking Theories}

Overspecification of the unmarked form has been criticized by Andrews (1990) and Blevins (1995) as leading to loss of significant linguistic generalizations. The most fundamental generalization to be captured is what Jakobson (1984) recognizes: the meaning of the unmarked form depends not statically on its inherent feature specifications, but dynamically on its relation to other elements in opposition to it. This generalization is what Andrews' (1982: 495) Morphological Blocking Condition in (4) is designed to capture:

(4) Morphological Blocking Condition (Andrews, 1982: 495)

If the constraint equations of a form $\mathrm{A}$ are a subset of those of a form $B$ from the same paradigm, and if the equations of B are satisfied at a position $\mathrm{X}$, then A may not be inserted at X.

Andrews' condition is a unification-based version of the Elsewhere Principle found in phonology (Anderson, 1969; Kiparsky, 1973): if both a specific and a general form from the same morphological paradigm are compatible with a syntactic position, the more specific one must be used. Because the lexical specifications of a verb or other head may unify with those of the syntactic context, Andrews' principle allows morphologically inflected forms to compete with and block certain syntactic elements in a construction. In the gender concord example, this condition would prevent the use of the unmarked masculine form where the marked feminine form is equally compatible because the empty set of features is a subset of any set, by definition. ${ }^{3}$

The dependence of the meaning of the unmarked form on competing elements from the same paradigm is illustrated by contrasting verbal paradigms in

\footnotetext{
${ }^{2}$ For discussion of further problems of feature-logic based theories, see Ingria (1990) and Johnson and Bayer (1995), who use properties of neutral forms to argue against unification, and Dalrymple and Kaplan (1997) for a rebuttal and unification-based counterproposal, utilizing a set-based theory of indeterminate feature values.

${ }^{3}$ See Andrews (1990: 519) for a reformulation in terms of subsumption of feature structures (Shieber 1986), rather than subsets of feature specifications.
} 
English and Ulster Irish (Andrews, 1990). The English present tense paradigm and Ulster Irish conditional paradigm are shown in (5). The marked forms are shown in boldface.

\begin{tabular}{|c|c|c|c|}
\hline English pres & it tense paradigm: & Ulster Irish co & ditional pa \\
\hline Singular & Plural & Singular & Plural \\
\hline 1 hit & hit & chuirfinn & chuirfimis \\
\hline hit & hit & chuirfeá & chuirfeadh \\
\hline hits & hit & 3 chuirfeadh & chuirfeadh \\
\hline
\end{tabular}

In English the unmarked form (hit) is used in the complement of morphosyntactic environments of the marked form (the third person singular):

(6) I/you/*he/*she/we/they hit the ball.

The same is true in Ulster Irish: the unmarked conditional form chuirfeadh is used in the complement of the morphosyntactic environments of the marked forms (the first person singular, first person plural, and second person singular):

$$
\begin{aligned}
& \text { Chuirfeadh }{ }^{*} \text { mé } / *^{*} \text { tu } / *^{*} \text { muid/sibh/sé/sí/siad isteach ar an phost sin. } \\
& \text { put.Cond I/you.SG/we/you.PL/he/she/they in on the job that } \\
& { }^{*} \mathrm{I} /{ }^{*} \text { you }(\mathrm{sg}) /{ }^{*} \text { we/you }(\mathrm{pl}) / \mathrm{he} / \text { she/they would put in for that job.' }
\end{aligned}
$$

How do we know from these facts alone that the forms hit in English and chuirfeadh in Ulster Irish are indeed unmarked in Jakobson's sense? In the domain of morphosyntax, unlike the domain of lexical meaning in Jakobson's donkey example, it is difficult to find contexts in which a putatively unmarked form can substitute for a marked form and thus demonstrate the presence of the inclusive meaning. The reason is that morphosyntactic constraints are generally too rigid to allow arbitrary substitution in grammatical constructions. This fact indeed has led to criticisms of Jakobson's definition of unmarkedness by Kuryłowicz, Dokulil, and other members of the Prague School (Dokulil, 1994). They have argued that in morphosyntax the unmarked forms are better understood in terms of ambiguity, having primary and secondary meanings, than in terms of the general, inclusive meaning described by Jakobson. What evidence is there then that the meaning of these morphologically unmarked forms is in fact general rather than ambiguous?

On the Jakobsonian definition the inherent meaning of the unmarked is general (nonspecific or vague) and its specific interpretations in various contexts 
depend on the marked form(s) to which it is in opposition. Hence there is a dynamic relation between the unmarked and marked forms. If the paradigm grows or shrinks in its marked forms, then the use of the unmarked form correspondingly diminishes or extends, augmenting or diminishing its range of specific interpretations. Thus Andrews (1990: 525) surveys the variation in use of verb forms in Irish dialects. The general tendency is that as the number of marked (inflected) forms increases from North to South, the use of the general (uninflected) forms correspondingly decreases. (In some areas there is a situation of free variation, with both marked and unmarked variants of certain categories in use; but Andrews notes (1990: n. 24, 530) that the cooccurring forms are sometimes reported to be differentiated by social register, suggesting the presence of closely related sociolinguistically competing grammars.) This dynamic relation is not captured by ambiguity analyses, for they provide no intrinsic connection between the loss of a marked form and the addition of its meaning to the unmarked form. The loss of inflected forms could simply lead to unfilled gaps in the paradigm, for example; or the gaps could be filled by extensions of other inflected forms.

To capture linguistic generalizations of this kind, syntactic theories must have some mechanism to represent competition among related morphosyntactic expressions. Though blocking was earlier applied in generative grammar to kinship terms and words (Gruber, 1973; Aronoff, 1976), Andrews' Morphological Blocking Principle (1982, 1984, 1990), couched within the LFG framework, is the first proposal within the generative tradition to capture morphosyntactic blocking. Blevins (1995) extends Andrews' proposal to HPSG by adding structured lexical paradigms to global feature type hierarchies ordered by subsumption and disjointness. In the distributed morphology framework, a rule-based theory of morphosyntax (Lumsden, 1992; Halle and Marantz, 1993; and Bonet, 1995), there is competition between more or less specified lexical items for insertion into a fully specified syntactic tree; the competition is implemented by rule ordering. For example, Lumsden (1992: 480) proposes that "A form that is specified for a relevant feature value must be inserted before a form that is unspecified for that feature." (This theory also admits ordering of morphological rules that nonmonotonically alter featural composition.) 


\section{Some Limitations of Blocking Theories}

The lexical blocking approaches to morphosyntactic competition all depend on two ideas. The first is that lexical forms compete for insertion into the same syntactic position. The field of competition is thus narrowly localized to a single preterminal $\left(\mathrm{X}^{0}\right)$ in the syntactic structure. The second idea is that a more specific or featurally complex form preempts a more general, featurally simple form. The possible relations of competing forms are thus restricted in terms of content to featural subsumption.

These restrictions are not intrinsic to the concept of paradigmatic competition, however. A more abstract conception of the paradigm is evident in the classic work of the European structuralists and the Prague School (represented by Jakobson). There the paradigm is viewed as a set of oppositions or dimensions of contrasts in general categories of meaning, a view which informs modern feature-based conceptions of inflectional morphology as well (e.g. Matthews, 1972; Anderson, 1992). In an important development in theoretical morphosyntax, Vincent and Börjars (1996) and Börjars, Vincent, and Chapman (1997) show that this abstract way of defining the paradigm can be captured in modern feature-logic based theories of syntax such as LFG and HPSG. Instead of restricting the paradigm to sets of words that can be lexically inserted into the same syntactic position in a tree, they expand the paradigm to sets of forms of expression (whether words or phrases) that correspond to the same type of feature structure. They argue that this model of the paradigm can play an explanatory role in the synchronic distribution and historical development of periphrases, suppletion, and pronominal inflections.

This more general conception of paradigm makes the prediction that paradigmatic competition could occur between morphological and syntactic forms of expression of the same general categories of meaning; in particular, blocking could cross the boundaries of $\mathrm{X}^{0}$ categories into the phrasal domain. And indeed, this phenomenon is widely attested. Blocking is implicit in periphrasis itself. Greenberg (1966: 30) observes that periphrasis is an instance of 'defectivation', Hjelmslev's (1953) term for the propensity of marked categories to have defective paradigms. As an example Greenberg gives the perfective verbal system in Latin, where the active verb has a perfect inflection but the (marked) passive verbal form relies on periphrastic expressions for the perfect. (Börjars, Vincent, and Chapman (1997) provide the same example with an analysis using LFG feature structures.) In such cases a syntactic form is used where the morphological paradigm is defective. If we return to the Ulster Irish exam- 
ples in (5) and (7), we see that syntactic constructions (namely a verb plus pronominal subject) fill the gaps in the inflectional paradigm (second plural, third singular, and third plural). The synthetic forms block the use of the syntactic construction to convey the specific information that is already expressed morphologically. In this way the blocking relation crosses the boundaries of the word into the syntactic domain.

A case of periphrasis in Basque is cited by Poser (1992: 122) as an example of the blocking of phrasal constructions by lexical items: in Basque a phrasal construction is used for progressive aspect except with verbs that have a progressive inflection. Another example of blocking from morphology into syntax cited by Poser (and already analyzed as morphosyntactic blocking by Andrews (1984)) is English comparative and superlative adjectival inflections, which are supplemented with phrasal forms where adjectives are uninflected:

(8) cheaper/cheapest, ${ }^{*}$ more $/{ }^{*}$ most cheap

*expensiver/*expensivest, more/most expensive

Poser (1992) hypothesizes that blocking of phrases by words is permitted only where the phrases are 'small categories' consisting entirely of $\mathrm{X}^{0}$ categories and created by morphological rules (see also Sells (1996)). But this structurally local characterization of morphosyntactic blocking cannot account for the Ulster Irish cases, where as we saw in (7), the entire periphrastic construction containing a main verb and a subject pronoun is blocked by the synthetic verbs which are inflected for subject pronominal features. The Irish main verb and subject can constitute an entire clause - quite a large category in its constituency. Nor would the small category hypothesis explain the English comparative, for although Poser (1992: 127) assumes that more intelligent is a small category consisting entirely of $\mathrm{X}^{0} \mathrm{~s}$, syntactic work on English comparatives (e.g. Bresnan, 1973) reveals a full $\mathrm{X}^{\prime \prime}$ phrasal structure for comparative measure phrases: witness [How much more] expensive is it? - It is [so much more] expensive, [exactly three times more] expensive. Nor would the Latin passive example plausibly be restricted to a small category, since there a single verb form competes with a major phrasal configuration [V VP] or [I VP]. Consequently the blocking of a syntactic construction by a morphological word cannot be so narrowly localized in $\mathrm{X}^{\prime}$-theoretic terms as Poser (1992) proposes.

Compared with other generative blocking theories, feature-logic based theories of morphological blocking (e.g. Andrews, 1990; Blevins, 1995) greatly extend the explanatory scope of the Elsewhere Principle into syntax. For example the competition within the Ulster Irish conditional paradigm is easily 
explained by Andrews (1990) because he captures the periphrastic relation by means of LFG feature structures, not by the operation of morphological rules on $\mathrm{X}^{0}$ categories. In LFG, crucially, words and phrases, though constructed from different elements and by different principles of composition, may specify feature structures of the same type (Bresnan and Mchombo, 1995; Bresnan, 1998a; Nordlinger, 1998). All feature-logic based theories share this property to a greater or lesser extent (e.g. Blevins, 1995; Ackerman and Webelhuth, 1998; Goldberg, 1996). In Andrews' (1990) analysis of the Irish synthetic inflections (5) the marked verb forms specify several attributes of their clauses: namely, the main predicator, the conditional mood, and the pronominal subject for certain persons and numbers. Andrews represents these by a complex feature structure (f-structure in LFG); a version of this type of analysis is illustrated in (9):

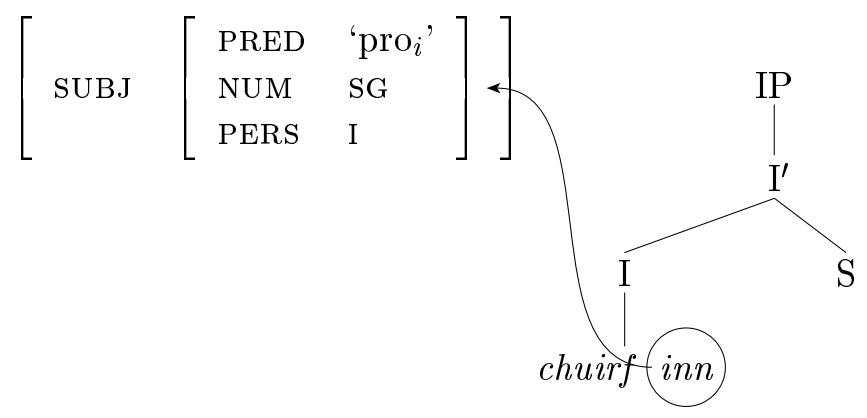

The unmarked verb forms are blocked in syntactic contexts that express the same constellation of information, represented by a similar complex feature structure arising from the unification of the head verb and subject pronoun feature structures with that of the clause (Andrews, 1990: 519). Blocking in the English adjectival comparatives is explained by Andrews (1984) in the same framework. Many other cases of the blocking of syntactic phrases by morphologically formed words have been documented and explained in feature-logic based theories of syntax: in Chichewa (Bresnan and Mchombo, 1987: 76875; Bresnan, in press a), Hungarian and Estonian (Ackerman, 1990; Ackerman and Webelhuth, 1997), Japanese and Korean (Sells, 1997a,b), Russian (King, 1995), and Persian (Goldberg, 1996). Both Andrews (1990) and Sadler (1997) analyze blocking between clitic-head constructions and phrasal pronominal constructions in French, Spanish, and Welsh, suggesting the quasi-morphological status of verbal clitics in these languages.

Despite the success of the feature-logic based theories of morphosyntactic blocking, these blocking theories nevertheless have other limitations stemming 
from the basic idea of a more specific or complex form preempting the lexical insertion of a more general or simple form into a periphrastic construction. Blocking is predicted only in the special case where one lexical item is more specified than another (that is, where one is properly subsumed by the other informationally). What happens when two forms compete but are not related by proper subsumption? Their features might only intersect, for example, each being unspecified for some feature of the other so that two different dimensions of markedness could be at play (Avery Andrews personal communication, May 1997). The blocking theories say nothing principled about such cases, but they exist.

Consider the verb are, which is the most general form in the suppletive paradigm for present tense be in Standard English:

\begin{tabular}{l|ll} 
& sg & pl \\
\hline 1 & am & are \\
2 & are & are \\
3 & is & are
\end{tabular}

The hypothesis that are is general in its meaning (unmarked in a Jakobsonian sense) rather than ambiguous would be supported by the existence of English dialects in which the historical person-number neutralization has converged on are. Such dialects exist. According to the Survey of English Dialects (Orton and Dieth, 1962-) are is generalized to the first person singular Are I?, I are in some localities of the Southern Counties (Vol. 4, Part 3: 1121, 1131-2, 11347) and the East Midland Counties (Vol. 3, Part 3: 1287, 1299, 1302). These dialects retain marking only for third singular of present tense be:

(11) Southern and East Midland Counties (Orton et al., 1962-71)

\begin{tabular}{l|ll} 
& sg & pl \\
\hline 1 & are & are \\
2 & are & are \\
3 & is & are \\
I are. Are I?
\end{tabular}

Although I have not found neutralization of all persons in the present, there are dialects which converge on were across all persons in the past. For example, in the West and East Midlands nonstandard dialects described by Cheshire, 
Edwards, and Whittle (1993: 80) there occur I were singing. So were John. Mary weren't singing: ${ }^{4}$

(12) West and East Midlands (Cheshire, Edwards, and Whittle, 1993: 80):

\begin{tabular}{l|ll} 
& $\mathrm{sg}$ & $\mathrm{pl}$ \\
\hline 1 & were & were \\
2 & were & were \\
3 & were & were
\end{tabular}

I were singing. So were John. Mary weren't singing.

In addition to the evidence from dialect variation, there is rare but telling evidence within Standard English showing that the general form are can replace the specific first-person singular form am in certain contexts. For most of the verb forms in (10), a negative affix - n't can be attached. (The contracted form of the negation - n't is often called a clitic, but Zwicky and Pullum (1983) argue convincingly that it has become an affixal negation.) However, the negative paradigm has a gap in the first person:

\begin{tabular}{l|ll} 
& sg & pl \\
\hline 1 & & aren't \\
2 & aren't & aren't \\
3 & isn't & aren't
\end{tabular}

In declarative sentences the gap is filled by the coexisting syntactic expression am not. But this syntactic form is unavailable in presubject position in questions:
a. * Am not I going?
b. I am not going.

In just this position in Standard English, the general aren't may fill the gap:

(15) a. Aren't I going?

b. *I aren't going.

\footnotetext{
${ }^{4}$ This dialect can be heard spoken by the unemployed Sheffield steelworkers' families portrayed in the British motion picture 'The Full Monty'.
} 
The fact that aren't does not occur in the declarative construction (15b) could be explained by the availability of the less marked syntactic form for this construction (14b). If so, then we have here a syntactic construction competing with an equivalent morphological one, as observed by Dixon (1982: 236-8) and Bresnan (in press a). (Of course, it needs to be explained why another competing construction Am I not going? does not suffice to block Aren't I going?, as Hudson (1997) rightly observes, and why blocking is not observed in coexisting forms such as isn't and is not. We return to both these questions below in Section 4. $)^{5}$

Interestingly, morphological blocking fails to explain this phenomenon. The negatively inflected form aren't in (15b) is neither more general nor more specific than $a m$ in the syntactic construction am not in (14b); am specifies person and number, but not negation, while aren't specifies negation but not person and number. Even if we enlarge the comparison to aren't and am not, treating am not as a 'small construction' in Poser's (1992) sense, we cannot explain the phenomenon. In Poser's as in all the morphosyntactic blocking theories, a word or smaller syntactic construction preempts an equivalent larger construction, in a kind of economizing of phrasal structure (cf. Bresnan, 1998a, forthcoming a; Sells, 1997a; Ackerman and Webelhuth, 1997, 1998; Sadler, 1997). Here, however, the syntactic construction is blocking the morphological form.

The same kind of competition between syntactic and morphological expressions of negation occurs in other English dialects. In some Scottish dialects, amn't may be used (Hughes and Trudgill, 1979: 14), but is restricted just as aren't is in the dialects which use that form (Dixon, 1982: 237; Richard Hudson, personal communication, April 7, 1997):

\section{(16) Scottish English dialects}

Amn't I your friend?

*I amn't your friend.

In Hiberno-English, in contrast, amn't is used in both positions (Jim Mcloskey, personal communication, October 1996; Siobhán Cottell, personal communication, April 7, 1997):

\section{Hiberno-English \\ Amn't I your friend? \\ I amn't your friend.}

\footnotetext{
${ }^{5}$ Hudson's (1997) own analysis using multiple inheritance involves overspecification of the general form aren't.
} 
What would explain these variations? Unlike Hiberno-English, Scottish English has a distinct clitic nae for sentence negation, which cannot invert (Brown, 1991: 80, 97-8; April McMahon, personal communication, October 29, 1997):

(18) He couldnae have been working.

*Couldnae he have been working?

These facts suggest that the native Scottish clitic nae is competing with the English - n't and blocking it. (Again it needs to be explained why another competing construction of Scots, Am I no your friend? does not also block Amn't I your friend? (Hudson, 1997). This question is addressed in Section 4.) These facts, too, are unexplained by morphological blocking, for the two negative elements are not distinguished by featural subsumption. Nor does the "smaller" (affixal) form of negation block the "larger" (clitic) form: as the contrast between (16) and (17) shows, the morphological form appears only where the clitic form is unavailable.

In sum, competition between morphological and syntactic forms of expression is correctly predicted by the feature-logic based models of the paradigm (Andrews, 1990; Blevins, 1995; Börjars, Vincent, and Chapman, 1997), given the classic conception of paradigmatic competition. Yet we have no real explanation for the full range of morphosyntactic competition that has been documented. The blocking theories of markedness localize the field of competition too narrowly in syntactic structure or too restrictively in morphosyntactic content. Optimality Theory (Prince and Smolensky, 1993) suggests a more general approach.

\section{Markedness in Optimality Theory}

Optimality Theory (OT) is a general theory of constraint interaction and comparative grammaticality. The basic structure of OT grammar is shown in (19) as a function from inputs to outputs. ${ }^{6}$ The inputs in this case are phonological segment strings and the outputs are syllabifications of the strings according to a simplified CV theory (Prince and Smolensky, 1993; Smolensky, 1996a).

\footnotetext{
${ }^{6}$ This original conception has recently been generalized to abstract away from the inputoutput function (Smolensky, 1996b). Nevertheless, the schema shown is useful as one illustrative instantiation of the general theory.
} 
(a) inPut CANDidates OUtPut

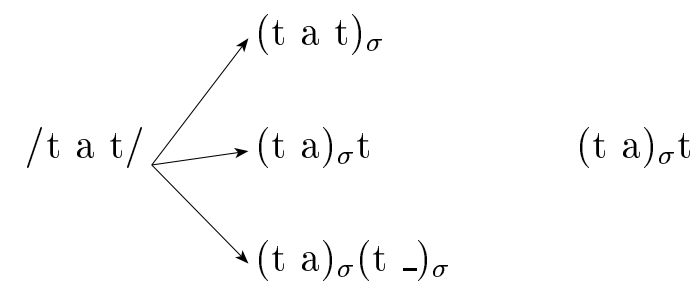

(b) GEN: INPUT $\Rightarrow$ CANDIDATES

(c) EVAL: CANDIDATES $\Rightarrow$ OUTPUT

A generator GEN produces candidate structural analyses or realizations of the input, and these are evaluated according to a function EVAL, whose basic properties are given in $(20):^{7}$

(20) EVAL

(i) A universal Constraint Set; constraints conflict and are violable.

(ii) A language-particular strict dominance ranking of the Constraint Set.

(iii) An algorithm for harmonic ordering: The optimal/most harmonic/least marked candidate ( $=$ the output for a given input) is one that best satisfies the top ranked constraint on which it differs from its competitors.

Two fundamental requirements of the theory must be noted. First, GEN must be universal. That is, the input and the candidate set are the same for all languages. Systematic differences between languages arise from different constraint rankings, which affect how the candidates are evaluated (Prince and Smolensky, 1993; Smolensky, 1996a). Secondly, to ensure learnability the input

\footnotetext{
${ }^{7}$ The general algorithm for determining the optimal, or most harmonic output, is given by Tesar and Smolensky (1996).
} 
must be recoverable from the output and the output itself must contain the overt perceptible data (Tesar and Smolensky, 1996).

Now in the domain of morphosyntax, universality of the input would be ensured by an abstract multidimensional space of dimensions of contrast as formally modelled by complex feature structures. Recoverability of the input from the overt perceptible output would be ensured by a well-defined correspondence between feature structures and the types of overt forms of expression which may realize them. Both of these requirements can be met by taking the morphosyntactic GEN to be one of the feature-logic based models of morphosyntax. This line of research is being actively developed in LFG (Choi, 1996, forthcoming; Bresnan, 1998b,c, in press a,b, forthcoming b,c; Sells, 1997b, 1998b; Butt, Dalrymple, and Frank, 1997; Frank, King, Kuhn, and Maxwell, 1998; Morimoto, 1998; Vincent, 1998a,b; Johnson, forthcoming; Lee, 1998). In what follows I will therefore assume for morphosyntax that the universal input is modelled by sets of f-structures and the universal candidate set consists of pairs of a cstructure and its corresponding f-structure, which may be matched to the input f-structure by a correspondence theory of input-output relations (cf. McCarthy and Prince, 1995; Bresnan, in press a,b, forthcoming c). ${ }^{8}$ The overall scheme is illustrated (with simplifications) in (21). ${ }^{9}$ Following Jakobson (1984) and Andrews (1990), we may assume that morphosyntactic candidates may have general (nonspecific or vague) meanings; generality is represented by fewer feature specifications. Output indeterminacy of this sort must not be confused with underspecification in the phonological sense (Steriade, 1995). The latter involves the omission of features in underlying structures which are required at the overt level.

\footnotetext{
${ }^{8}$ The candidates could equally well be represented as c-structures with 'annotated' feature structures, as in some variants of LFG (Andrews and Manning, 1993) and construction grammar (Goldberg, 1996). On the formal architecture of LFG see Dalrymple et al. (eds) (1995) and Bresnan (forthcoming a).

${ }^{9}$ Among the simplifications are these: the label 'BE' stands for an index to the appropriate lexical semantics, '2' and 'SG' should specify the person and number of an argument (the subject) of the verb, and 'PRES' should specify a clausal property. Some issues involving detailed representations are discussed by Butt, King, and Dalrymple (1997) and Dalrymple and King (1997). Note also that monovalent (privative) features are used here; these are represented uniquely by their values. The natural contrasts among sets of such features (e.g. SG vs. PL) follow from their inherent meanings, obviating a purely formal representation by equipollent feature values. Such a representation is not necessary to the present theory, however, and the standard feature-logic attribute value system can be substituted.
} 
(21) An Optimality Theoretic Framework for Morphosyntax

INPUT

CANDIDATES

OUTPUT

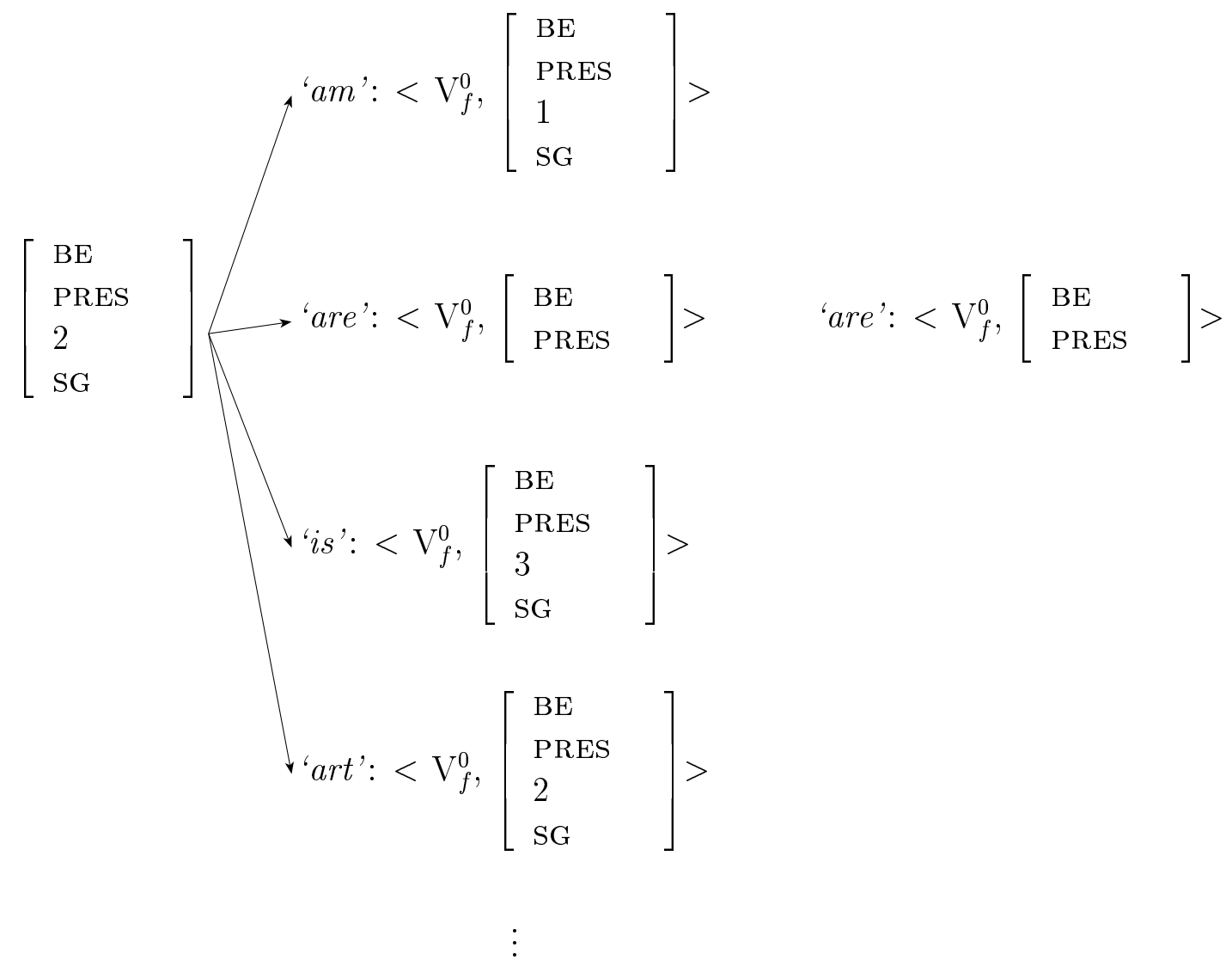

On this conception of GEN the input represents language-independent 'content' or points in the multidimensional spaces of possible grammatical and lexical contrasts, to be expressed with varying fidelity by the candidate forms, which carry with them their own interpretations of that content. For each input, GEN enumerates the set of all possible types of formal realizations of that input that are available across languages. In morphosyntax as in phonology, systematic variation is derived by the rerankings of universal constraints rather than by language-particular specifications of differences in input or lexical inventory. Thus it is presumably a systematic fact about English that it has auxiliary verbs. In (21) $\mathrm{V}_{f}^{0}$ stands for a finite auxiliary or 'functional' verb. 
There are many other categorial realizations of the input among the candidate set-for example as main verbs, verbal inflections, copular particles, or no structure at all; by hypothesis these alternatives are all less optimal than the auxiliary verb analysis under the constraint ranking for English. Likewise, it is a systematic fact about English that person and number distinctions are neutralized throughout the verbal paradigm except in third singular present (and in first singular present for be). As shown in (21) the candidate set includes a second person singular present tense form. The fact that second person verb forms are lacking in Standard English is a result of this neutralization; it follows from their nonoptimality under the current constraint ranking, and their presence in nonstandard English dialects (such as those of Somerset where art or be'st are used (Ihalainen, 1991: 107-8)) arises from alternative rankings, as we will see.

What is not systematic is not derived from the general theory but must be specified as a language-particular property. Thus in (21) the names 'am', 'is', 'are' in quotation marks stand for the English spellings (pronunciations) of candidates which have the abstract universal characterizations represented in angled brackets. These spellings are a language-particular property of English which distinguishes it from other languages independently of systematic differences in constraint ranking. Given the constraint ranking for English, the English-particular lexicon is a sampling of the output (Smolensky, 1996a) that associates pronunciations and other unsystematic properties with the abstract morphosyntactic characterization. (The form pronounced 'art' is of course no longer used in Standard English; it is included here simply as a convenient label for the candidate form which most faithfully matches the input in (21), but is nevertheless not optimal under the constraint rankings of present-day Standard English, which neutralize second person.)

Now markedness in Optimality Theory results from the relative ranking of the two types of constraints shown in (22) and (23) - constraints on faithfulness to the input ('FAITH') and constraints on the structural markedness or wellformedness of forms ('STRUCT') (Prince and Smolensky, 1993; Smolensky, 1996a).

\section{(22) Faithfulness constraint (FAITH):}

FAITH $^{\mathrm{P} \& \mathrm{~N}}$ : preserve input person and number in the output ${ }^{10}$

\footnotetext{
${ }^{10}$ FAITH $^{\text {P } ~ \& ~ N}$ comprises both IDENT-IO(PERS \& NUM), MAX-IO(PERS \& NUM) in the correspondence theory of faithfulness (McCarthy and Prince 1995). See Bresnan forthcoming b for further discussion.
} 


\section{(23) Structural markedness constraints (STRUCT):}

(a) ${ }^{*} \mathrm{PL},{ }^{*} \mathrm{SG}$

(b) $*_{2}, *_{1}, *_{3}$

'FAITH ${ }^{\mathrm{P} \& \mathrm{~N}}$ ' is violated by any candidate which fails to match the input in both person and number. Note that faithfulness in fusional morphology is assumed here to respect sets of values, such as person and number combined in FAITH $^{\text {P \& N } .11}$ Different faithfulness constraints may be instantiated for various morphosyntactically defined domains (Urbanczyk, 1995; Benua, 1995; Smith, 1997). In Standard English the three present-tense verbal paradigms (be, modal verbs, and other verbs) are thus represented by three different FAITH ${ }^{P} \& \mathrm{~N}$ constraints, of which we will be concerned here only with FAITH $_{b e}^{\mathrm{P} \& \mathrm{~N}}$.

In general, faithfulness constraints favor featurally more complex forms, and hence more informative forms. Opposing faithfulness, however, are structural markedness constraints, which penalize the complexity of forms. The STRUCT constraints ${ }^{*} 2,{ }^{*} 1,{ }^{*} 3$ are respectively violated by candidates specified for second, first, and third person values. Faithfulness constraints serve the major communicative function of preserving contrasts, making it possible for languages to have perceptibly different expresions for different meanings. But markedness constraints work to erode these contrasts by simplifying expressions.

Suppose now that the structural markedness constraints are ranked with respect to the faithfulness constraints as in $(24)$. ( ${ }^{6} c_{1} \gg c_{2}$ ' means that constraint $c_{1}$ outranks constraint $c_{2}$ in the constraint hierarchy. The ranking relations of constraints separated by commas are not specified here.)

$$
{ }^{*} \mathrm{PL},{ }^{*} 2 \gg \mathrm{FAITH}_{b e}^{\mathrm{P} \& \mathrm{~N}} \gg{ }^{*} \mathrm{SG},{ }^{*} 1,{ }^{*} 3
$$

\footnotetext{
${ }^{11}$ Faithfulness to sets of values cannot be eliminated by the local conjunction (Legendre, Smolensky, and Wilson 1995) of constraints on single feature values. The local conjunction of FAITH(PERS) and FAITH(NUM) is violated only when both conjuncts are violated, Hence in tableau (26) the local conjunction interpretation would favor fully specified forms $i s, a m$ that partly match the input over the general form (are) that completely fails to match the input. Logical conjunction could be used instead (Hewitt and Crowhurst, 1996). Nigel Vincent (personal communication, November 11, 1997) suggests that logical conjunction of constraints may be characteristic of fusional and suppletive morphology; see Börjars and Vincent (1997) for discussion of specific properties of fusional morphology.
} 
The ranking of the markedness constraints for second person and plural above the faithfulness constraint means that violations of the former are worse than violations of the latter. Thus it is worse to express these features than to be unfaithful to the input by failing to preserve them. Hence a general form unmarked for second person or plural number will be preferred over candidates specifically marked for these features. On the other hand, the ranking of faithfulness above the other markedness constraints means that it is worse to fail to express the input features of singular number and first or third person than to bear the complexity penality against marking them. The end result of these rankings will be that specific forms for first or third person singular will be optimal when they match the input, as we see in (25), and the general unmarked form will be optimal elsewhere, as we see in (26). In OT, this is how one could derive the blocking of the general form are of the present tense be paradigm by the specific forms am, is.

In these tableaux the constraints are ordered from left to right according to their relative ranking. Violations of constraints are indicated by $\mathrm{a}^{*}$, and the ! denotes a fatal violation, rendering a candidate nonoptimal. The optimal candidate(s) are designated by . Constraint evaluations which have no effect in determining the outcome are shaded gray. Thus the marks incurred in (25) by 'am', which violates ${ }^{*} 1$ and ${ }^{*} \mathrm{SG}$ by bearing the features 1 and $\mathrm{SG}$, are nevertheless overridden by the fatal marks incurred by its unfaithful competitor candidates and have no role here in determining the outcome:

$$
\text { input: [BE PRES } 1 \mathrm{SG}]
$$

\begin{tabular}{|c|c|c|c|}
\hline & ${ }^{*} \mathrm{PL},{ }^{*} 2$ & FAITH $_{b e}^{\mathrm{P}}$ \& N & ${ }^{*} \mathrm{SG},{ }^{*} 1,{ }^{*} 3$ \\
\hline 'am': [BE PRES 1 SG] & & & $* *$ \\
\hline 'is': [BE PRES 3 SG] & & ${ }^{*} !$ & $* *$ \\
\hline 'are': [BE PRES] & & ${ }^{*} !$ & \\
\hline 'art': [BE PRES 2 SG] & $* !$ & $*$ & $*$ \\
\hline
\end{tabular}

(26) input: [BE PRES 2 SG]

\begin{tabular}{|r|c|c|c|}
\hline & ${ }^{*} \mathrm{PL},{ }^{*} 2$ & $\mathrm{FAITH}_{b e}^{\mathrm{P}} \& \mathrm{~N}$ & ${ }^{*} \mathrm{SG},{ }^{*} 1,{ }^{*} 3$ \\
\hline 'am': [BE PRES 1 SG] & & ${ }^{*}$ & $* !$ \\
\hline 'is': [BE PRES 3 SG] & & ${ }^{*}$ & $* ! *$ \\
\hline 'are': $[$ [BE PRES] & & ${ }^{*}$ & \\
\hline 'art': [BE PRES 2 SG] & $* !$ & & $*$ \\
\hline
\end{tabular}


Observe in (26) that if the markedness constraint against second person were to be demoted below faithfulness, the second person form would now become optimal, as in the Somerset dialects (Ihalainen, 1991: 107-8). Conversely, if the markedness constraint against first person were promoted above faithfulness, are would be generalized to first singular, as in the Southern and East Midland dialects (11).

A number of researchers in OT have proposed that in the initial state of the language learner all structural markedness constraints dominate faithfulness constraints; maximal unmarked forms are thus optimal during the initial stages of language acquisition. Then during the acquisition of marked forms, markedness constraints are subsequently demoted, allowing marked forms to become optimal. (See Smolensky (1996a) for discussion and references; cf. Hale and Reiss (1997) for an opposing view; for a symmetric demotion-and-promotion learning strategy, see Boersma (1997).) On this view the absence of a marked form from a language would reflect the persistence of the initial high ranking of the relevant markedness constraints. In this case the learner never encounters the evidence needed to demote the relevant markedness constraints.

\section{Analytic and synthetic negation in English}

We have now seen how the present OT framework for morphosyntax can capture blocking effects. (See Sells $(1997 \mathrm{a}, \mathrm{b})$ for further examples from Japanese and Korean.) Unlike the blocking theories the present framework can also explain competition effects that are not localized to a single preterminal node in a syntactic tree and which do not follow the default logic of feature subsumption hierarchies. The competition between analytic and synthetic negation in English dialects sketched in Section 2 will provide our demonstration.

We begin by observing that the overall structure of our framework for morphosyntax (21) applies as well to larger syntactic structures (Bresnan, in press a): 


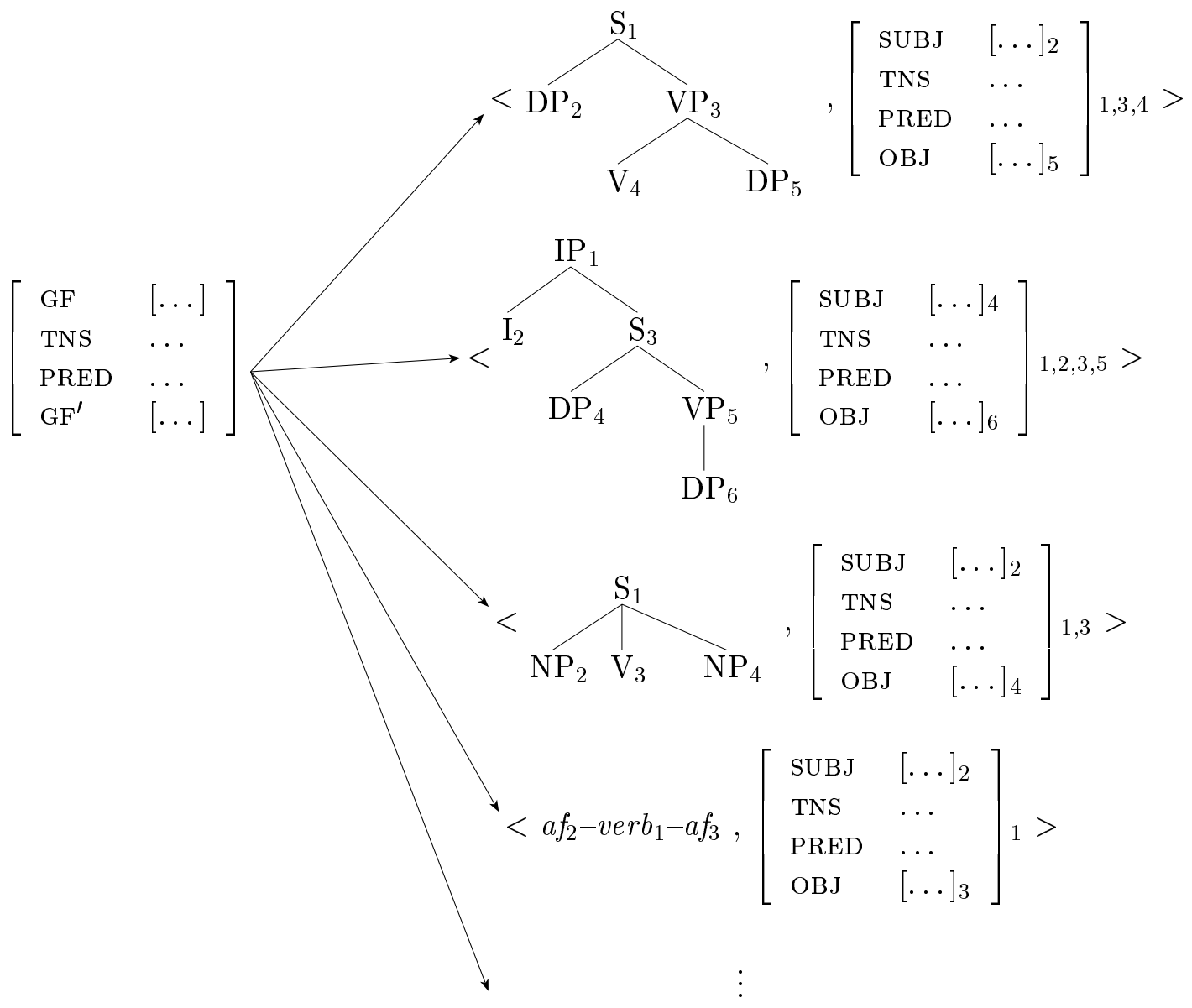

The inputs are again f-structures (with undifferentiated argument function types $\mathrm{GF}, \mathrm{GF}^{\prime}$ ), and the candidates are again pairs of expressions and their corresponding f-structures, but this time at the level of sentence structure (as in LFG and similar syntactic frameworks). Expressions of syntax are actually composite, consisting of c-structures and their lexical instantiations. ${ }^{12}$

To determine what constraints will apply, we must next set English negation within the morphosyntactic typology of sentence negation. Klima (1964) distinguishes sentential negation from constituent negation by a number of tests

\footnotetext{
${ }^{12}$ Hence, the candidates are more accurately thought of as n-tuples of lexical strings, trees, feature structures and their correspondence functions.
} 
including polarity reversal in confirmatory tag questions. Sentential negation can take scope over the entire sentence and reverse the polarity of tags, as illustrated by the postverbal not in (28a). Constituent negation cannot, as illustrated by $u n$ - and not in $(28 \mathrm{~b}-\mathrm{c})$ :

(28) a. Louise is not happy, is she?

(sentential negation)

b. Louise is unhappy, isn't she?

(constituent negation)

c. Louise likes not being happy, doesn't she? (constituent negation)

Sentential negation may also be expressed in English by negated or inherently negative quantifier phrases, as in $(28 \mathrm{a}, \mathrm{b})$ :

(29) a. Not many books survived the fire, did they?

b. No books survived the fire, did they?

From this it would seem that sentential negation could simply be defined as any expression of negation having the sentence as its semantic scope. However, the expressions standardly used to negate sentences do not always have sentential scope semantically. For one thing, the actual semantic scope of sentential negation varies with the focus structure of the sentence (Jackendoff, 1972). ${ }^{13}$ For another, certain sentence operators like the initial adverb in (30b) and the modal verb must in(31b) take scope over sentential negation (cf. Stockwell, Schachter and Partee, 1973: 248; Payne, 1985: 200):

(30) a. He hasn't often paid taxes, has he? $\operatorname{NOT}(\operatorname{OFTEN}(\mathrm{S}))$

b. ?Often he hasn't paid taxes, has he?

$\operatorname{OFTEN}(\operatorname{NOT}(\mathrm{S}))$

(31) a. He can't pay taxes, can he?

$\operatorname{NOT}(\operatorname{POSSIBLE}(\mathrm{s}))$

\footnotetext{
${ }^{13}$ For example, the negation in (i) (adapted from Payne (1985: 199)) has a reading in which its semantic scope is restricted to the focused PP, yet still passes the test for sentential negation in requiring polarity reversal in a confirmatory tag:

(i) Celia didn't kiss John IN THE RAIN, did she? ('It's true of Celia, isn't it, that she didn't kiss John in the rain' or 'It's true, isn't it, that it was not in the rain that Celia kissed John)
} 
Thus 'sentential negation' does not take sentential scope under all conditions, only under conditions of neutral focus and the absence of widest-scope sentence operators.

To circumvent these problems of identification, Payne (1985) defines standard negation as the expression of (sentential) negation in the basic sentences of a language, which are the minimal sentence constructions that exclude optional dependents such as adverbials and modifiers. Standard negation will coincide with sentential negation (semantically scoping over the sentence) in the simplest cases, and thus identified, it can be extended to cases where the semantic scope of the same expression of negation is reduced by focus or widest-scope sentence operators. Non-standard negation will then encompass constituent negation as in $(28 \mathrm{~b}, \mathrm{c})$ and any types of sentential negation which are expressed only in non-basic sentences (e.g. (29a,b)). We will be concerned here only with standard negation.

Languages vary in their repertoires of negative expressions; many lack negative quantifiers, for example. But according to Payne (1985: 223) all languages possess standard negation and typologically, standard negation is overwhelmingly a verbal category. Crosslinguistically, it appears as a negative lexical verb or auxiliary, a negative verbal inflection, or as an analytic negation expression adjoined to a verbal category, in which are included here V, VP, I (the postsubject finite auxiliary position) and C (the inverted verb position in English). Only rarely does standard negation appear as a nominal category, and the single instance cited by Payne (1985: 228) shows signs of a deverbal origin. Following the OT markedness logic presented in the previous section, these assumptions suggest the markedness constraints in (32).

\section{(32) Structural markedness constraints:}

(a) $*_{\text {NEG-C, }} *_{\text {NEG-I }}, *_{\text {NEG-V }}, *_{\text {NEG-VP: }}$ mark an analytic negation expression adjoined to $\mathrm{C}, \mathrm{I}, \mathrm{V}, \mathrm{VP}$.

(b) ${ }^{*}$ NINFL- $V_{f}^{0},{ }^{*}$ NINFL- $\mathrm{V}_{l e x}^{0}:$ mark a synthetic negatiion expression, inflecting functional (auxiliary) or lexical verbs.

(c) *NEG-LEX-V: mark a negation expression lexicalized as a verb. 
Note that these structural markedness constraints apply to the expression component of the candidates in the present framework (27). Expressions are formally modelled by c-structures, representing the overt, perceptible configuration of syntactic elements. Thus the constraints on analytic negation such as $*_{\text {NEG-C }}$ and $*_{\text {NEG-I }}$ are violated by c-structures containing the substructures (33a) and (33b), respectively:

a.

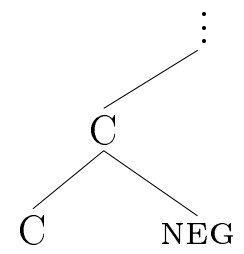

b.

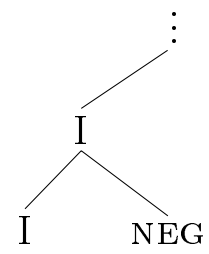

No syntactic movements are assumed in this constraint-based, output-oriented framework, and none need be, because the correspondence mapping between the parallel c- and f-structures ${ }^{14}$ functionally replaces the coindexing between different substructures of the same tree invoked in derivational representations of movement (Bresnan, in press a). Thus, rather than concern ourselves with a hypothetical base-generated tree position from which expressions of standard negation must be moved to their observable surface positions (as first proposed by Klima (1964) and still assumed in derivational syntactic frameworks), we simply let GEN enumerate the full typological space of possible surface realizations of standard negation, with corresponding f-structures showing the clausal polarity information they provide. From this point of view, (33a,b) are two independent structures produced by GEN by simple adjunction of NEG directly to $\mathrm{C}$ (occupied by a complementizer or pre-subject verb) or I (occupied by the finite auxiliary in English). ${ }^{15}$ In sum, the constraints in (32) simply impose marks against specific surface verbal positions or categories where negation might be overtly realized. (The *NINFL constraints are a special case of Sells' (1997a,b) "Avoid Affix".) Intuitively, these constraints penalize the additional structural complexity contributed by various expressions of negation at the lexical, morphological, or syntactic level.

Opposed to these markedness constraints is the faithfulness constraint of (34):

\footnotetext{
14_and a-structures (Bresnan and Zaenen, 1990).

${ }^{15}$ Variable positioning of verbs within the clause follows from the correspondence mapping; see Kroeger (1993), King (1995), Bresnan (in press a, forthcoming a), Berman (1996, 1997, 1998), Sadler (1997), Sells (1998a,b) and the references cited in these.
} 


\section{(34) Faithfulness constraint:}

FAITH $^{\text {NEG }}$ : preserve input scope of negation in the output ${ }^{16}$

Our interpretation of FAITH ${ }^{\mathrm{NEG}}$ will be that any of the verbal expressions of negation in $(32 \mathrm{a}-\mathrm{c})$ can parse the sentential scope of standard negation, but only the structurally appropriate expressions can parse constituent negation. Thus a negation expression attached to a VP can in principle have either sentence scope or constituent scope over $\mathrm{VP}$, while a negation expression attached to $\mathrm{I}^{0}$ can have sentence (IP) scope but not constituent scope over VP. ${ }^{17}$

By ranking FAITH ${ }^{\text {NEG }}$ among the family of markedness constraints for expressions of negation, we can derive the particular inventory of expressions of negation used in a given language following the same logic of markedness as in the preceding section. For example, if all of the structural markedness con-

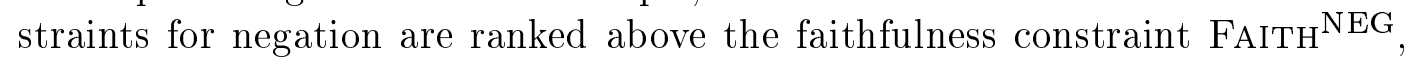
the markedness of negative expressions will be worse than the failure to express negation. The resulting grammar would define a hypothetical language severely limited in its expressibility by the absence of specialized expressions for negation. Demotion of the constraint marking verbal lexicalization of negation (32c) below FAITH ${ }^{\text {NEG }}$ would yield a language whose inventory of negative expressions for standard negation consists of lexical verbs. An example would be the Nilo-Saharan language Majang, which employs a transitive negating verb $k u_{-}^{-}$"which is neither an affix nor an auxiliary, but a full verb root" (Unseth, 1994: 12).

$$
\begin{aligned}
& \text { Majang (Unseth 1994) } \\
& \ldots \gg \text { FAITH }^{\text {NEG } \gg *_{N E G-L E X-V}}
\end{aligned}
$$

Swahili expresses standard negation synthetically by means of affixation to lexical verb stems, and this inventory follows from the ranking illustrated in (36), where the sole structural markedness constraint demoted below faithfulness is that against negatively inflected lexical verbs:

(36) Swahili (Ashton, 1982)

$$
\ldots \gg \text { FAITH }^{\mathrm{NEG}} \gg{ }^{*} \text { NINFL- } \mathrm{V}_{\text {lex }}^{0}
$$

\footnotetext{
${ }^{16}$ Technically, the semantic scope information is not represented in f-structures, which are unspecified with respect to scope relations (Genabith and Crouch, 1996; Dalrymple et al., 1997) but in a parallel information structure of the input.

${ }^{17}$ This generalization does not rule out the attraction of standard negation scope to focal phrases, as discussed above, but it does exclude a NEG-I expression from negating only a VP in the absence of special focus or other operators.
} 
Russian, according to King (1995), expresses negation analytically by adjoining ne to I:

(37) Russian (King, 1995)

$$
\ldots \gg \text { FAITH }^{\text {NEG }} \gg *_{N E G-I}
$$

This framework can also illuminate the variable forms of standard negation in English dialects.

Standard English has both analytic negation (not) and synthetic negation (the negative verbal affix $-n$ 't). Restricting attention first to analytic negation, we see that the same invariant negation expression not is used to negate sentences as in (38a) and nonfinite VP constituents as in (38b), leading to ambiguities as in (38c):

(38) a. She does not see him.

b. She kept not seeing him.

c. She could not have been working. (sentence negation)

(VP-constituent negation)

(ambiguous)

One possible analysis within our framework would be to say that not in (38) is always adjoined to nonfinite VP, where it can (under the right conditions) parse either sentential scope or VP-scope negation. This account would be descriptively attractive from an English-internal standpoint, because it capitalizes on the sameness of form of not in its various uses. Yet it offers no explanation for the fact that standard not requires the proximity of a finite auxiliary or modal verb on its left: ${ }^{18}$

(39) a. * Marianne not left.

b. * Marianne left not.

c. Marianne did not leave.

An alternative analysis is proposed (with minor differences ignored here) by Payne (1985) and Bresnan (in press a). According to this analysis, the ambiguity of (38c) represents a choice between NEG-I right-adjoined to the modal/finite auxiliary position $\mathrm{I}^{0}$ or NEG-VP left-adjoined to the VP:

\footnotetext{
${ }^{18}$ Grimshaw (1997) offers an account of this fact within OT assuming a NegP; see Bresnan (in press a) for discussion.
} 
(40) a. He [could not] have been working.

NEG-I

b. He could [not have been working].

NEG-VP

In support of this two-structure analysis of English not, Payne (1985: 240-1) points out that it is typologically common for languages to have different forms of negation for main (or fully tensed) and subordinate clauses. Observe that with the modal can, English orthography actually distinguishes the two forms. As shown in (41), the NEG-I form is spelled as a single word cannot, while the NEG-VP construction is spelled as two separate words can not:

(41) a. He cannot have been working. $\neg(\operatorname{POSS}(\operatorname{work}($ he $)))$

b. He can (just/simply) not have been working. $\operatorname{POSS}(\neg(\operatorname{work}($ he $)))$

We will make use of this convenient orthographic representation of the distinction in what follows.

The two-structure analysis can be expressed in the present framework by the constraint ranking in (42):

$$
\begin{aligned}
& \text { English) } \\
& \ldots{ }^{*}{ }_{\mathrm{NEG}-\mathrm{C}} \gg \text { FAITH }^{\mathrm{NEG}} \gg{ }^{*}{ }_{\mathrm{NEG}-\mathrm{VP}} \gg *_{\mathrm{NEG}-\mathrm{I}}
\end{aligned}
$$

This ranking allows two analytic forms of negation into the Standard English inventory: not adjoined to VP and not adjoined to $\mathrm{I}^{0}$. By hypothesis both can parse wide scope (sentence) negation, but only the former can parse constituent negation of VP. Now assume that the input specifies sentential scope negation;

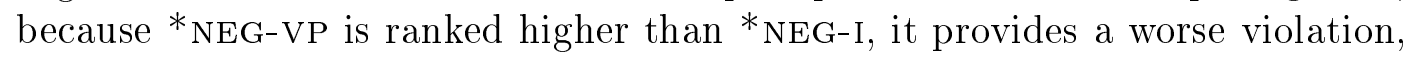
and therefore not adjoined to VP will be less harmonic than not adjoined to $\mathrm{I}^{0}$ for this reading. But when the input specifies VP-scope negation, not adjoined to VP will be optimal by our interpretation of FAITH ${ }^{\mathrm{NEG}}$ (34). This ranking therefore derives the contrast seen in (41), assuming that cannot has not adjoined to $\mathrm{I}^{0}$, while can not has not adjoined to VP. See Tableaux (43):

\begin{tabular}{|c|c|c|c|}
\hline & FAITH $^{\text {NEG }}$ & ${ }^{*}{ }_{\text {NEG-VP }}$ & ${ }^{*}$ NEG-I \\
\hline \hline input: $\neg$ (POSS(work(he)) & & & \\
\hline he cannot have been working & & & $*$ \\
\hline he can not have been working & & $* !$ & \\
\hline \hline input: POSS( $\neg($ work(he)) & & & \\
\hline he cannot have been working & $* !$ & & $*$ \\
\hline he can not have been working & & $*$ & \\
\hline
\end{tabular}


How does this analysis apply to the other modals? The modal verbs could, may (in the permission sense), and need are like can in allowing standard negation to have wider (sentential) scope (cf. (31a)). With these modal verbs, therefore, the structural ambiguity between NEG-I and NEG-VP coincides with a clear semantic difference in scope as above. But may (in the possibility sense), might, and will are widest-scope sentential operators like must in (31b). With widest-scope modals the structural ambiguity between NEG-I and NEG-VP obviously does not coincide with the scope difference. Neverthless, both negation structures are syntactically available with these modals, as (44) illustrates:

(44) a. You [must not] simply [not work].

b. He [may not] just [not have been working].

Thus the essential difference with these modals is that their faithfulness to the widest scope property overrides faithfulness to wide-scope negation. A full Optimality Theoretic analysis of the English modal verbs would take us too far afield in the present study, however. In what follows can or could will continue to be our exemplar, because they conveniently signal the structural ambiguity of negation by a scope ambiguity.

The proposed analysis of Standard English not finds support in the Hawick Scots dialect of English, as very usefully described by Brown (1991). Analytic negation in Hawick Scots takes two forms: there is a negative clitic nae, which attaches to the finite auxiliary or modal, and a negative isolate no:

(45) Hawick Scots (Brown, 1991: 83):

(a) ? She couldnae have told him, but she did.

('It was impossible for her to have told him, but she did tell him.')

(b) She could no have told him, but she did.

('It was possible for her not to have told him, but she did tell him.')

The clitic nae in Hawick Scots closely corresponds to the Standard English not adjoined to $\mathrm{I}^{0}$. First, as shown in (45a), nae unambiguously takes wide scope over the modal, creating a contradiction with the following conjunct. Second, like the Standard English not, nae cannot invert with the auxiliary:

(46) a. * Isnae he coming?

(Hawick Scots-Brown, 1991: 80) 
Assuming that the inverted auxiliary of both dialects is the $\mathrm{C}^{0}$ position, these shared properties of Standard English and Hawick Scots reflect the ranking of

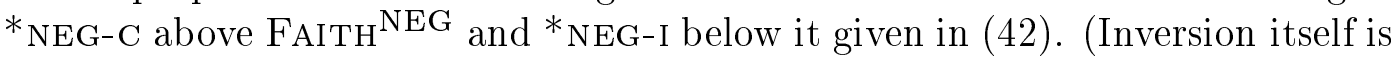
not treated here; see Grimshaw (1997) and Bresnan (in press a).) A structure will incur a mark under ${ }^{*}$ NEG-C when syntactic negation (not in Standard English, nae in Scots) appears in the inverted position (adjoined to $\mathrm{C}^{0}$ ). Only the overt perceptible position of the negative element is considered in assessing STRUCT marks, by the design of our general framework (21).

The Hawick Scots isolate no corresponds to English not adjoined to VP; it "normally shows narrow scope negation" (Brown, 1991: 83). However, Brown (1991: 83) notes that there is "a small complication": a sentence like She could no have told him is "potentially ambiguous between a narrow scope reading and a negative stressed wide scope reading." This fact would follow if we assume that clitics and other reduced, atonic forms cannot express what Brown calls stressed negation; only forms that can carry primary stress have this property. By ranking a FAITH ${ }^{\text {STRESS }}$ constraint together with FAITH $^{\text {NEG }}$ among the FAITH constraints, we allow the need to express stressed negation to override the greater markedness of the isolate no as a competitor to the clitic nae: ${ }^{19}$

$$
\begin{aligned}
& \text { Hawick Scots: } \\
& \ldots{ }^{*} \text { NEG-C } \gg \text { FAITH } \gg{ }^{*} \text { NEG-VP } \gg{ }^{*} \text { NEG-I }
\end{aligned}
$$

This ranking gives us the basic generalizations for the use of Hawick Scots no and nae in simple sentence declaratives and interrogatives, as described by Brown (1991). In the following tableaux the set of faithfulness constraints-

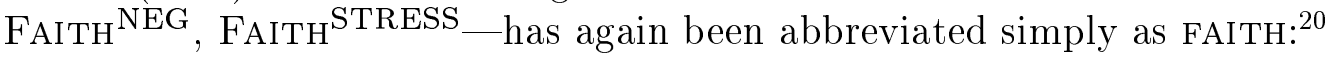

\footnotetext{
${ }^{19}$ I use the terms "stressed negation," FAITH ${ }^{\text {STRESS }}$, and STRESS as convenient shorthand for what may well involve constraints on focus structure.

${ }^{20}$ I set aside here the constraints which yield inversion for yes/no questions; see Bresnan (in press a) for the specifics assumed here.
} 


\begin{tabular}{|l|c|c|c|c|}
\hline & ${ }^{*}$ NEG-C & FAITH & ${ }^{*}$ NEG-VP & ${ }^{*}$ NEG-I \\
\hline \hline input: $\neg$ (POSS(work(he))) & & & & \\
\hline he couldnae work & & & & $*$ \\
\hline he could no work & & & $* !$ & \\
\hline \hline input: STRESS $\neg($ POSS(work(he))) & & & & \\
\hline he couldnae work & & $* !$ & & $*$ \\
\hline \hline he could no work & & & $*$ & \\
\hline input: Q( $\neg($ POSS(work(he))) & & & & \\
\hline couldnae he work? & $* !$ & & & \\
\hline could he no work? & & & $*$ & \\
\hline
\end{tabular}

The results are straightforward. In declaratives, the clitic nae is the optimal form for expressing sentence-scope negation; the isolate no is possible with stressed negation and required for VP-scope negation. In interrogatives, the isolate no is the optimal form for expressing sentence negation, regardless of stress.

Under the analysis proposed here (following Bresnan (in press a)), Standard English is very similar to Hawick Scots in its inventory of syntactic expressions of (analytic) negation, differing in the spelling (pronunciation) of the two analytic forms:
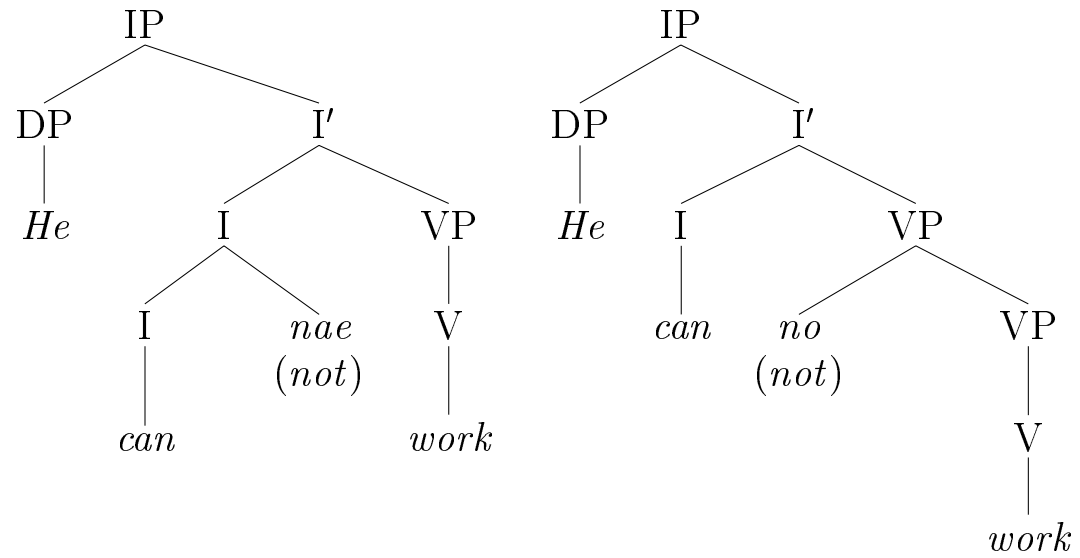

Let us now turn to synthetic negation. The negative affix - $n$ 't has the same form in the two dialects, but somewhat different properties. Consider first 
Standard English. In declaratives the -n't form alternates as an expression of wide scope negation with not adjoined to I:

(50) a. He can't have been working.

$$
\begin{aligned}
& \neg(\operatorname{POSS}(\operatorname{work}(\text { he }))) \\
& \neg(\operatorname{POSS}(\operatorname{work}(\text { he }))) \\
& \operatorname{POSS}(\neg \operatorname{work}(\text { he })))
\end{aligned}
$$$$
\text { b. He cannot have been working. }
$$$$
\text { c. He can not have been working. }
$$

In interrogatives having unstressed wide-scope negation, $-n$ 't widely replaces not in the contemporary spoken standard: ${ }^{21}$

(51) a. Can't he have been working?

b. Can he not have been working?

c. \% Can he not have been working?

(marked: very formal or stilted)
$\mathrm{Q}(\neg(\operatorname{POSS}(\operatorname{work}($ he $))))$

$\mathrm{Q}(\operatorname{POSS}(\neg(\operatorname{work}($ he $))))$

$\mathrm{Q}(\neg(\operatorname{POSS}(\operatorname{work}($ he $))))$

This pattern results from the constraint ranking shown in (52). The constraint * NINFL- $V_{f}^{0}$ is the structural markedness constraint for negative inflections on functional verbs (auxiliaries and modals). It is here grouped with the lowest ranked of the markedness constraints on analytic negation, * NEG-I from (42).

(52) Spoken Standard English:

$$
\ldots{ }^{*}{ }_{\mathrm{NEG}-\mathrm{C}} \gg \mathrm{FAITH} \gg{ }^{*} \mathrm{NEG-VP} \gg{ }^{*} \mathrm{NEG}-\mathrm{I},{ }^{*}{ }_{\mathrm{NINFL}-\mathrm{V}_{f}^{0}}
$$

The properties of the negative forms given in (50)-(51) follow:

\footnotetext{
${ }^{21}$ Palmer and Blandford (1969: 293) observe that negative sentences on the pattern Does John not drink coffee? are occasionally used in very formal speech, adding "but most good speakers feel that this style is stilted and unnatural".
} 


\begin{tabular}{|c|c|c|c|c|c|}
\hline & & $*$ NEG-C & FAITH & *NEG-VP & ${ }^{*}$ NEG-I, ${ }^{*}$ NINFL-V $V_{f}^{0}$ \\
\hline \multicolumn{6}{|c|}{ input: $\neg($ POSS(work(he))) } \\
\hline 舑 & he can't have been working & & & & $*$ \\
\hline \multirow[t]{3}{*}{ 吗 } & he cannot have been working & & & & $*$ \\
\hline & he can not have been working & & & $* !$ & \\
\hline & input: $\mathrm{Q}(\neg($ POSS(work(he $))))$ & & & & \\
\hline & can't he have been working? & & & & $*$ \\
\hline & cannot he have been working? & $* !$ & & & \\
\hline & can he not have been working? & & & $* !$ & \\
\hline \multicolumn{6}{|c|}{ 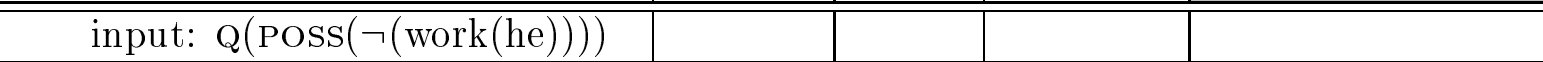 } \\
\hline & can't he have been working? & & $* !$ & & $*$ \\
\hline & cannot he have been working? & $* !$ & * & & \\
\hline & can he not have been working? & & & * & \\
\hline
\end{tabular}

Observe that in (53) two alternate forms - can't and cannot - are optimal in simple declaratives. This results from treating ${ }^{*}$ NEG-I and ${ }^{*}$ NINFL- $V_{f}^{0}$ as tied constraints in (53). In the present context, this device is merely a simplification, abstracting away from the exact conditions (such as stress, emphasis or style) under which the two forms may be differentially used. ${ }^{22}$ Within OT, tying of constraints is one way in which optional alternate forms can arise (Tesar and Smolensky, 1996), although in a large grammar consisting of massive numbers of constraints there are certain to be some that distinguish the forms. Another way to model optionality is to adopt partially ordered rankings which define sets of coexisting competing grammars (Anttila, 1997, to appear). Yet another way in which optional alternant forms can arise is from allowing variable ranking, such as random variation around ranking values of constraints on a continuous scale, which can produce different frequencies of production of optionally varying forms (Boersma, 1997) as well as gradient judgments (Hayes, in press).

The main point of this analysis of the English synthetic negation is that its relatively unmarked status effectively eliminates NEG-VP from the competition for expressing sentential negation. (It appears, of course, when narrower scope

${ }^{22}$ Thus we can eliminate the tie by having FAITH ${ }^{\mathrm{FEAT}} \gg *_{\text {NEG-I }} \gg *_{\text {NINFL-V }}^{0}$, which in declaratives would make can't optimal for negative inputs without FEATure and cannot optimal for negation with FEAT. In general, our tied constraints could be eliminated with a more fine-grained theory of the input than there is scope for here. 
is required, as in the examples like They will obviously not have time to change cited by Kim and Sag (1996).)

Consider now synthetic negation in Scottish English. The same English form - n't is also used, but it is considerably more marked. In Hawick Scots, $-n ' t$ is lexically restricted to a subset of the verbs which can be negated with nae (Brown, 1991: 93). Thus can, must, will do not have -n't forms, though could does:

cannae, mustnae, willnae, couldnae, ...

*can't, *mustn't, *won't, couldn't, ...

Brown (1991: 80) remarks that $-n$ 't is "not usually available in main clause negatives" but "seems to occur freely in tags", where ... isn't he? contrasts with ... is he no? in both intonation and pragmatic implication. The markedness of the English form in Scottish English generally is reinforced by Miller's (1993) sociolinguistic description, where - $n$ 't is said to be preferred by educated speakers in formal contexts (114). An asymmetry in the distribution of - $n$ 't in Scottish English is also pointed to by Dixon (1982: 237), cited in Section 2 above (16):

(55) Scottish English dialects (Dixon 1982)

Amn't I your friend?

*I amn't your friend.

Exactly this asymmetric distribution of $-n^{\prime} t$ would result from the constraint ranking in (56):

(56) Scottish English:

$\ldots{ }^{*}$ NEG-C $\gg$ FAITH $\gg{ }^{*}$ NEG-VP, ${ }^{*}$ NINFL- $V_{f}^{0} \gg{ }^{*}$ NEG-I

Here ${ }^{*}$ NINFL- $\mathrm{V}_{f}^{0}$ is ranked higher, and thus makes a worse markedness violation, than in Standard English (52). ${ }^{23}$ As a result $-n$ 't forms in Scottish English compete less well with the ${ }^{*}$ NEG-I form than in Standard English. The results are shown in (57):

\footnotetext{
${ }^{23}$ Again the tie between constraints is a simplification to be replaced by a more fine-grained theory of the factors affecting choice of forms (cf. n. 22).
} 


\begin{tabular}{|c|c|c|c|c|c|}
\hline & & $*_{\mathrm{NEG}-\mathrm{C}}$ & FAITH & ${ }^{*}$ NEG-VP, ${ }^{*}$ NINFL-V ${ }_{f}^{0}$ & *NEG-I \\
\hline & input: $\neg$ (POSS(wor & & & & \\
\hline & he couldn't work & & & $* !$ & \\
\hline & he couldnae work & & & & $*$ \\
\hline & he could no work & & & $* !$ & \\
\hline & input: STRESS $\neg(\mathrm{PO}$ & & & & \\
\hline & he couldn't work & & $* !$ & $*$ & \\
\hline & he couldnae work & & $* !$ & & * \\
\hline 唡 & he could no work & & & $*$ & \\
\hline & input: $\mathrm{Q}(\neg(\mathrm{POSS}(\mathrm{w}$ & & & & \\
\hline 唡 & couldn't he work? & & & $*$ & \\
\hline & couldnae he work? & $* !$ & & & \\
\hline & could he no work? & & & * & \\
\hline
\end{tabular}

This ranking explains why - $n$ 't appears only where nae cannot appear. It also predicts a contrast in the scope of NEG-VP in Scottish English and spoken Standard English. In spoken Standard English questions, as we saw in (53), the inverted contracted form - $n$ 't has replaced the sentence-scope use of NEGVP not. In Scottish English, in contrast, - $n^{\prime} t$ is more marked and fares less well against the sentence-scope use of NEG-VP no in interrogatives.

In areas of Ireland the negative affix shows the same markedness rank as in Standard English, yielding a symmetrical pattern, as noted in Section 2 above:

(58) Hiberno-English

Amn't I your friend?

I amn't your friend.

The contrast between (55) and (58) is quite interesting theoretically. The essential difference between the two dialects is that ${ }^{*}$ NINFL- $\mathrm{V}_{f}^{0}$ is higher ranked (hence more marked) compared to NEG-I in Scots than in Hiberno-English:

(59) a. Hiberno-English:

$$
\ldots{ }^{*} \text { NEG-C } \gg \text { FAITH } \gg *_{\text {NEG-VP }} \gg{ }^{*} \text { NEG-I },{ }^{*} \text { NINFL- } V_{f}^{0}
$$

b. Scottish English:

$\ldots{ }^{*}$ NEG-C $\gg$ FAITH $\gg{ }^{*}$ NEG-VP, ${ }^{*}$ NINFL- $V_{f}^{0} \gg{ }^{*}$ NEG-I 
There is no evident structural basis for this difference in markedness. Compared to amn't, amnae is neither more economical in phrase structure nodes nor more specific in featural content, whether compared in parts or as a whole. ${ }^{24}$ Hence the preemption of amn't by amnae (where the latter is available) has no evident structural basis internal to Scots. Also unanswered in purely structural terms is why the NEG-I structure blocks NINFL- $V_{f}^{0}$ in Scots but not in Hiberno-English.

Thus the markedness difference between NINFL- $\mathrm{V}_{f}^{0}$ and NEG-I in the two dialects cannot be explained by the blocking theories. Nor should it be. NEG-I in Scots is of course the native Scots form nae, while NEG-I in Hiberno-English is the Standard English form not. The fact that *NINFL- $\mathrm{V}_{f}^{0}$, a Standard English form - n't in both dialects, is more marked compared to NEG-I in Scots than in Hiberno-Irish may simply reflect the social competition between the Scots and the Standard English forms of expression. If so, the competition cannot be explained in terms of purely structural properties of the forms themselves, but instead reflects historical and social factors that have shaped the universally available typological possibilities in slightly different ways through constraint ranking. Recall from Section 3 that the language-particular lexicon is a sampling of the output that associates spellings, or pronunciations, and other unsystematic properties with the abstract morphosyntactic characterization. Here the unsystematic property is the social value of the standard and nonstandard pronunciations of NEG-I. ${ }^{25}$

Standard English itself, as we noted in Section 2, lacks the first person singular negative form of be used in (58) and (55). Various reasons have been suggested for the presence of this gap. Dixon (1982) proposes a phonological reduction of $a m$ to $[a:]$ before $-n^{\prime} t$ to avoid the [mn] sequence. Another suggestion $^{26}$ is that ain't may be an older regular first person present negative form which became socially stigmatized after its use spread to other persons. What-

\footnotetext{
${ }^{24}$ Indeed, the opposite is true. am in amnae is less specific than amn't and equally economical in phrase structure nodes, occupying a single $\mathrm{I}^{0}$. Likewise, the entire verb plus clitic construction amnae is more complex in phrase structure nodes than amn't, and equally specific in features. Only if we invented a feature [SCOTS] and attached it to the entire complex of verb plus clitic, leaving the English form -n't unspecified for this feature, could we say that it amnae blocks amn't by proper featural subsumption. However, this move would take the native Scots form to be the marked form, despite the clear dialect-internal evidence that the English form - $n^{\prime} t$ is more marked; see the discussion surrounding (54) above.

${ }^{25} \mathrm{By}$ 'unsystematic' I mean 'not deriving from the abstract system of grammatical contrasts and structural expressions'. Social factors may of course also be systematized in language; formal politeness systems are one example.

${ }^{26}$-from a usage note, The American Heritage Dictionary.
} 
ever its causes, it manifests itself by the absence of a recognized pronunciation for the pair in (60), given our (simplified) framework of Section 3:

$$
\text { (60) ' ': < }<\mathrm{V}_{f}^{0}+\text { ninfl, }\left[\begin{array}{l}
\mathrm{BE} \\
\mathrm{PRES} \\
1 \\
\mathrm{SG} \\
\mathrm{NEG}
\end{array}\right]>
$$

To model accidental lexical gaps in OT, assume a highly ranked constraint which requires that candidates normally have pronunciations; ${ }^{27}$ the absence of a pronunciation for (60) will filter it out from the candidate set. Because it is the job of the lexicon to pair the inventory of abstractly characterized candidates selected by the constraint ranking with the unsystematic language-particular pronunciations by which they are used, this constraint is called LEX. ${ }^{28}$

The presence of this lexical gap in Standard English eliminates a competitor from the candidate set. To understand the results, consider first the tableaux in (61), which simply add LEx in a position dominating the spoken Standard English constraints of (53). The FAITH ${ }^{\text {NEG }}$ and FAITH ${ }^{\text {STRESS }}$ constraints are abbreviated as FAITH in (53).

27 'Normally' would refer to cases where the structural form of the candidate, represented by the left member of the pair in (60), is nonempty. Null structure occurs in some candidates, such as zero pronouns (Bresnan, in press a, forthcoming c; Grimshaw and Samek-Lodovici, 1998).

${ }^{28}$ This constraint is used only for truly accidental gaps, which cannot be explained systematically. The discovery of a explanation in terms of systematic constraints would allow the latter to replace LEX in our subsequent analysis. The LEX constraint follows suggestions of Edward Flemming (personal communication, Fall 1996) and Scott Myers (personal communication, April 1997). 
(61) Possible effect of a lexical gap (I):

\begin{tabular}{|l|c|c|c|c|c|}
\hline & LEX & ${ }^{*}$ NEG-C & FAITH & ${ }^{*}$ NEG-VP & ${ }^{*}$ NEG-I, * NINFL \\
\hline \hline (declarative, wide negative, $1 \mathrm{SG})$ & & & & & \\
\hline I amn't (60) working & $* !$ & & & & ${ }^{*}$ \\
\hline I am not working & & & & & $*$ \\
\hline I am $[$ not working] & & & & $* !$ & \\
\hline \hline (interrogative, wide negative, 1 SG) & & & & & \\
\hline Amn't (60) I working? & $* !$ & & & & $*$ \\
\hline Am not I working? & & $* !$ & & & \\
\hline Am I $[$ not working]? & & & & $*$ & \\
\hline
\end{tabular}

For declaratives the result is that the syntactic construction am not is optimal; ${ }^{29}$ for interrogatives, the syntactic construction with $\mathrm{am}$ inverted and not adjoined to VP is optimal. Here syntactic constructions with am ...not replace the missing first person singular negative inflected form of $b e$.

Though some speakers may avoid the lexical gap by using a syntactic construction everywhere, it is much more common (certainly in informal spoken Standard American English) to use Aren't I . . ?, the apparent "first person" aren't (Langendoen, 1970; Hudson, 1977, 1997; Dixon, 1982; Gazdar et al., 1982; Kim and Sag, 1996; Bresnan, in press a), as discussed in Section 2. ${ }^{30}$ What is happening is that faithfulness to person and number is sacrified in order to avoid the very marked use of VP-negation with wide scope. For these speakers, ${ }^{*}$ NEG-VP dominates FAITH $_{b e}^{\mathrm{P}} \& \mathrm{~N}$ in the constraint hierarchy, as shown in $(62)$ :

$$
\begin{aligned}
& *_{\text {NEG-VP }} \gg \text { FAITH }_{b e}^{\mathrm{P} \& \mathrm{~N}} \\
& \text { FAITH }_{b e}^{\mathrm{P} \& \mathrm{~N}} \gg *_{\text {NEG-I, }}{ }^{*}{ }_{\text {NINFL-V }}^{0}
\end{aligned}
$$

With all other constraint rankings the same as before, this means that it is a worse violation to use VP negation (for wide-scope input) than to violate faithfulness to number and person. The main result is shown in (63), where $\mathrm{F}^{\mathrm{NEG}}$ and $\mathrm{F}^{\mathrm{PN}}$ designate faithfulness to negation and to person and number, respectively.

\footnotetext{
${ }^{29}$ The choice between the full verb $a m$ and the reduced ' $m$ is an orthogonal issue that is not addressed here. See Pullum and Zwicky (1997) for discussion.

${ }^{30}$ See also n. 21 above.
} 
(63) Possible effect of a lexical gap (II):

\begin{tabular}{|l|c|c|c|c|c|c|}
\hline & LEX & ${ }^{*}$ NEG-C & F $^{\text {NEG }}$ & ${ }^{*}$ NEG-VP & F $^{\text {PN }}$ & ${ }^{*}$ NEG-I, *NINFL \\
\hline \hline (declarative, wide negative, 1 SG) & & & & & & \\
\hline I amn't (60) working & $* !$ & & & & & $*$ \\
\hline I aren't working & & & & & $* !$ & $*$ \\
\hline I am not working & & & & & & $*$ \\
\hline I am [not working] & & & & $* !$ & & \\
\hline \hline (interrogative, wide negative, 1 SG) & & & & & & \\
\hline Amn't (60) I working? & $* !$ & & & & & $*$ \\
\hline Aren't I working? & & & & & $*$ & $*$ \\
\hline Am not I working? & & $* !$ & & & & \\
\hline Am I $[$ not working]? & & & & $* !$ & & \\
\hline
\end{tabular}

Let us recall from Section 3 why the form aren't is optimal here. Consider the theory of person-number marking in Section 3. As expressions of third and first person singular, the special forms based on $i s$ and $a m$ are optimal, as shown in tableaux (64) and (65): ${ }^{31}$

(64) INPUT: [NEG $3 \mathrm{SG}$ ] (declarative)

\begin{tabular}{|r|c|c|c|c|c|c|c|}
\hline & LEX & ${ }^{*}$ NEG-C & $\ldots$ & $\mathrm{F}^{\text {PN }}$ & $\ldots$ & ${ }^{*} \mathrm{SG},{ }^{*} 1,{ }^{*} 3$ & $\ldots$ \\
\hline i isn't [NEG 3 SG] & & & & & & ${ }^{*}$ & \\
\hline ii is not [NEG 3 SG] & & & & & & $* *$ & \\
\hline iii aren't [NEG] & & & & $* !$ & & & \\
\hline iv are not [NEG] & & & & $* !$ & & & \\
\hline v am not [NEG 1 SG] & & & & $* !$ & & $* *$ & \\
\hline vi amn't (60) & $* !$ & & & $*$ & & $* *$ & \\
\hline
\end{tabular}

${ }^{31}$ Only the relevant features, constraints, and candidates are shown. 


\begin{tabular}{|r|c|c|c|c|c|c|c|}
\hline & LEX & ${ }^{*}$ NEG-C & $\ldots$ & $\mathrm{F}^{\mathrm{PN}}$ & $\ldots$ & ${ }^{*} \mathrm{SG},{ }^{*} 1,{ }^{*} 3$ & $\ldots$ \\
\hline i isn't [NEG 3 SG] & & & & $* !$ & & $* *$ & \\
\hline ii is not [NEG 3 SG] & & & & $* !$ & & $* *$ & \\
\hline iii aren't [NEG] & & & & $* !$ & & & \\
\hline iv are not [NEG] & & & & $* !$ & & & \\
\hline v am not [NEG 1 SG] & & & & & & $* *$ & \\
\hline vi amn't (60) & $* !$ & & & & & $* *$ & \\
\hline
\end{tabular}

Observe in (65) how the lexical gap corresponding to amn't in other dialects is filled by the analytic form am not. (66) shows that when the input conflicts with feature values of the most specified forms, the general forms will be optimal, as we expect:

$$
\text { INPUT: [NEG } 1 \text { PL] (declarative) }
$$

\begin{tabular}{|r|c|c|c|c|c|c|c|}
\hline & LEX & ${ }^{*}$ NEG-C & $\ldots$ & $\mathrm{F}^{\text {PN }}$ & $\ldots$ & ${ }^{*}$ SG, ${ }^{*} 1,{ }^{*} 3$ & $\ldots$ \\
\hline i isn't [NEG 3 SG] & & & & ${ }^{*}$ & & ${ }^{*}{ }^{*}$ & \\
\hline ii is not [NEG 3 SG] & & & & $*$ & & $* ! *$ & \\
\hline iii aren't [NEG] & & & & $*$ & & & \\
\hline iv are not [NEG] & & & & $*$ & & & \\
\hline v am not [NEG 1 SG] & & & & $*$ & & $* ! *$ & \\
\hline vi amn`t (60) & $* !$ & & & $*$ & & $* *$ & \\
\hline
\end{tabular}

Now in all these tableaux the analytic (not) forms are equally harmonic with the synthetic negative forms available as long as both are in postsubject position $\left(\mathrm{I}^{0}\right)$. When inverted (in $\mathrm{C}^{0}$ position), however, the analytic form will incur a mark by ${ }^{*}$ NEG-C, and the synthetic form becomes more harmonic. This is fine in all cases except for (65) (the first person singular input), where a synthetic first person singular form is lacking. The analytic form still cannot be used in this (inverted) case, which tells us that ${ }^{*}$ NEG-C must outrank the PARSE constraints at least. In just this case, the optimal candidate becomes aren't,

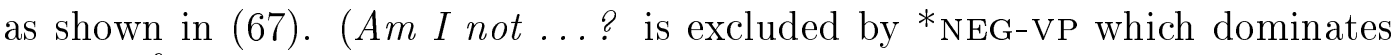
FAITH $_{b e}^{\mathrm{P} \& \mathrm{~N}}$ as in (63).) 


\begin{tabular}{|r|c|c|c|c|c|c|c|}
\hline & LEX & ${ }^{*}$ NEG-C & $\ldots$ & $\mathrm{F}^{\text {PN }}$ & $\ldots$ & ${ }^{*}$ SG, ${ }^{*} 1,{ }^{*} 3$ & $\ldots$ \\
\hline i isn't [NEG 3 SG] & & & & ${ }^{*}$ & & ${ }^{*}{ }^{*}$ & \\
\hline ii is not [NEG 3 SG] & & $* !$ & & ${ }^{*}$ & & $* *$ & \\
\hline iii aren`t [NEG] & & & & $*$ & & & \\
\hline iv are not [NEG] & & $* !$ & & $*$ & & & \\
\hline v am not [NEG 1 SG] & & $* !$ & & & & $* *$ & \\
\hline vi amn`t (60) & $* !$ & & & & & $* *$ & \\
\hline
\end{tabular}

We see, then, that the appearance of aren't in the inverted position for the first person singular follows from its unmarked status for person and number in the verbal paradigm for be, given the strong constraints against using the analytic forms with inversion. Its appearance in only the inverted position results from the competition by the more harmonic analytic form in the uninverted position. In the latter situation we have another case where a syntactic construction "blocks" a morphological one.

What is most striking about the use of negation in these English dialects is that the specific properties of the output form depend upon the other surface forms (both morphological and syntactic) that actively compete with it, and not on the details of the derivation of its formal structure, as in the classical generative approach to syntax. The results are attained by letting surface morphological and syntactic forms express the same kinds of abstract information, as in the feature-structure representations of syntax. Optimality Theory, incorporating a feature-logic based theory of the candidate set, shows us that small (and even externally motivated) differences in the evaluation of surface forms of expression can have visible and unexpected repercussions in the syntax and semantics of verbal negation and inversion.

Although we have been concerned here with variations among closely related dialects of English, the same overall framework for morphosyntax can be applied to much broader typological variations (e.g. Bresnan 1998a, in press $\mathrm{a}, \mathrm{b}$, forthcoming c) - an inviting project for future research. 


\section{References}

Ackerman, F. (1990). The morphological blocking principle and oblique pronominal incorporation in Hungarian. In K. Dziwirek, P. Farrell, and E. MejíasBikandi (eds), Grammatical Relations. A Cross-Theoretical Perspective (pp. 1-19). Stanford: CSLI Publications.

Ackerman, F. and Webelhuth, G. (1997). The composition of (dis)continuous predicates. In E. Katalin Kiss (ed), Acta Linguistica Hungarica: Special Volume on Syntax. To appear.

Ackerman, F. and Webelhuth, G. (1998). A Theory of Phrasal Predicates. Stanford: CSLI Publications.

Anderson, S. R. (1969). West Scandinavian Vowel Systems. Cambridge, MA: MIT Department of Linguistics Ph.D. dissertation.

Anderson, S. R. (1992). Amorphous Morphology. Cambridge: Cambridge University Press.

Andrews, A. D. (1982). The representation of case in modern Icelandic. In J. Bresnan (ed), The Mental Representation of Grammatical Relations (pp. 427-503). Cambridge: The MIT Press.

Andrews, A. D. (1984). Lexical insertion and the elsewhere principle in LFG. Canberra: Australian National University Department of Linguistics MS.

Andrews, A. D. (1990). Unification and morphological blocking. Natural Language 8 Linguistic Theory 8, 507-57.

Andrews, A. D. and Manning, C. (1993). Information spreading and levels of representation in LFG. Report No. CSLI-93-176. Stanford, CA: Center for the Study of Language and Information.

Anttila, A. (1997). Morphological Variation. Stanford: Stanford University Department of Linguistics Ph.D. dissertation.

Anttila, A. (To appear). Deriving variation from grammar. In F. Hinskens, R. van Hout, and L. Wetzels (eds), Variation, Change and Phonological Theory. Amsterdam: Benjamins.

Aronoff, M. (1976). Word Formation in Generative Grammar. Cambridge, MA: The MIT Press. 
Ashton, E. O. (1982). Swahili Grammar (Including Intonation). Essex: Longman.

Barbosa, P., Fox, D., Hagstrom, P., McGinnis, M., and Pesetsky, D. (eds), (1998). Is the Best Good Enough? Optimality and Competition in Syntax. Cambridge, Massachusetts: The MIT Press and MIT Working Papers in Linguistics.

Beckman, J., Dickey, L. and Urbanczyk, S. (eds), (1995). Papers in Optimality Theory. University of Massacusetts Occasional Papers 18. Amherst: University of Massachusetts.

Benua, L. (1995) Identity effects in morphological truncation. In Beckman et al. (eds), (pp. 77-136).

Berman, J. (1996). Topicalization vs. left-dislocation of sentential arguments in German. In Butt and King (eds).

Berman, J. (1997). Empty categories in LFG. In Butt and King (eds).

Berman, J. (1998). On the syntax of correlative es and finite clauses in German - an LFG analysis. In Proceedings of the ESSLLI-98 Workshop on Constraint-Based Theories of Germanic Syntax, Saarbrücken.

Blevins, J. P. (1995). Syncretism and paradigmatic opposition. Linguistics and Philosophy 18, 113-52.

Boersma, P. (1997). How we learn variation, optionality, and probability. On-line, Rutgers University: Rutgers Optimality Archive, ROA-221-1097, http://ruccs.rutgers.edu/roa.html.

Bonet, E. (1995). Feature structure of Romance clitics. Natural Language 86 Linguistic Theory 13, 607-47.

Börjars, K., Vincent, N., and Chapman, C. (1997). Paradigms, periphrases and pronominal inflection: a feature-based account. In G. Booji and J. van Marle (eds), The Yearbook of Morphology (pp. 1-26). Dordrecht: Kluwer Academic Publishers.

Börjars, K. and Vincent, N. (1997). Double case and the "wimpishness" of morphology. Paper presented at the Lfg97 Conference, Univerity of California, San Diego, July 9-11, 1997.

Bresnan, J. (1973). Syntax of the comparative clause construction in English. Linguistic Inquiry 4, 275-343. 
Bresnan, J. (1998a). Morphology competes with syntax: explaining typological variation in weak crossover effects. In Barbosa et al. (eds), (pp. 59-92).

Bresnan, J. (1998b) Markedness and morphosyntactic variation in pronominal systems. Paper presented at the workshop Is Syntax Different? Common cognitive structures for syntax and phonology in Optimality Theory, CSLI, Stanford University, December 12-13, 1998.

Bresnan, J. (1998c) Pidgin genesis in Optimality Theory. In Butt and King (eds).

Bresnan, J. (In press a). Optimal syntax. In Dekkers et al. (eds).

Bresnan, J. (In press b). The emergence of the unmarked pronoun: Chichewa Pronominals in Optimality Theory. BLS-23.

Bresnan, J. (Forthcoming a). Lexical-Functional Syntax. Oxford: Blackwell.

Bresnan, J. (Forthcoming b). The lexicon in Optimality Theory. Paper presented at Annual CUNY Conference on Human Sentence Processing, Special Session on the Lexical Basis of Syntactic Processing: Formal and Computational Issues, Rutgers University, March 20, 1998.

Bresnan, J. (Forthcoming c). The emergence of the unmarked pronoun. In Legendre et al. (eds).

Bresnan, J. and Mchombo, S. A. (1987). Topic, pronoun, and agreement in Chicheŵ. Language 63, 741-82.

Bresnan, J. and Mchombo, S. A. (1995). The lexical integrity principle: evidence from Bantu. Natural Language \& Linguistic Theory 13, 181-252.

Bresnan, J. and Zaenen, A. (1990). Deep unaccusativity in LFG. In K. Dziwirek, P. Farrell, and E. Mejías-Bikandi (eds), Grammatical Relations: A Cross-Theoretical Perspective (pp. 45-57). Stanford: CSLI Publications.

Brown, K. (1991). Double modals in Hawick Scots. In Trudgill and Chambers (eds.), (pp. 74-103).

Butt, M., Dalrymple, M., and Frank, A. (1997). An architecture for linking theory in LFG. In Butt and King (eds) 1997.

Butt, M. and King, T. H. (eds), (1996). LFG-Workshop. Proceedings of the First LFG Conference, Rank Xerox Research Centre, Grenoble, August 2628, 1996. On-line, CSLI Publications: http://www-csli.stanford.edu/publications/. 
Butt, M. and King, T. H. (eds), (1997). Proceedings of the LFG97 Conference, University of California, San Diego. On-line, CSLI Publications: http://www-csli.stanford.edu/publications/.

Butt, M. and King, T. H. (eds), (1998). Proceedings of the LFG98 Conference, University of Queensland, Brisbane. On-line, CSLI Publications: http://www-csli.stanford.edu/publications/.

Cheshire, J., Edwards, V., and Whittle, P. (1993). Non-standard English and dialect levelling. In Milroy and Milroy (eds.) (53-96).

Choi, H.-W. (1996). Optimizing Structure in Context: Scrambling and Information Structure. Stanford, CA: Stanford University Department of Linguistics doctoral dissertation. On-line, Rutgers University: Rutgers Optimality Archive, http://ruccs.rutgers.edu/roa.html.

Choi, H.-W. (Forthcoming). Focus scrambling and reconstruction in binding. In Legendre et al. (eds).

Dalrymple, M. and Kaplan, R. M. (1997). A set-based approach to feature resolution. In Butt and King (eds.) 1997.

Dalrymple, M., Kaplan, R. M., Maxwell, J. M., and Zaenen, A. (eds), (1995). Formal Issues in Lexical-Functional Grammar. Stanford: CSLI Publications.

Dekkers, J., van der Leeuw, F. and van de Weijer, J. (eds), (In press). Optimality Theory: Phonology, Syntax, and Acquisition. Oxford: Oxford University Press.

Dixon, R. M. W. (1982). Semantic neutralisation for phonological reasons. In Where Have All the Adjectives Gone? and other essays in Semantics and Syntax (pp. 235-8). Berlin: Mouton Publishers.

Dokulil, M. (1994). On morphological oppositions. In P. A. Luelsdorff, J. Panevová, and P. Sgall (eds), Praguiana. 1945-1990 (pp. 113-30). Amsterdam: John Benjamins. (Original work published 1958.)

Frank, A., King, T. H., Kuhn, J., and Maxwell, J. M. (1998). Optimality Theory style constraint ranking in large scale LFG grammars. In Butt and King (eds) 1998.

Gazdar, G., Pullum, G., and Sag, I. (1982). Auxiliaries and related phenomena in a restrictive theory of grammar. Language 58, 591-638. 
Genabith, J. van and Crouch, R. (1996). F-structures, QLFs and UDRSs. In Butt and King (eds.) 1996.

Goldberg, A. (1996). Words by default: optimizing constraints and the Persian Complex Predicate. BLS 22, 132-46.

Greenberg, J. (1966). Language Universals. With Special Reference to Feature Hierarchies. The Hague: Mouton.

Grimshaw, J. (1997). Projection, heads, and optimality. Linguistic Inquiry 28, $373-422$.

Grimshaw, J. and Samek-Lodovici, V. (1998). Optimal subjects and subject universals. In Barbosa et al. (eds), (pp. 193-219).

Gruber, G. (1973). Hoa kinship terms. Linguistic Inquiry 4, 427-49.

Hale, M. and Reiss, C. (1997). Formal and empirical arguments concerning phonological acquisition. On-line, Rutgers University: Rutgers Optimality Archive, ROA-170-0197, http://ruccs.rutgers.edu/roa.html.

Halle, M. and Marantz, A. (1993). Distributed morphology and the pieces of inflection. In K. Hale and S. J. Keyser (eds), The view from Building 20 (pp. 111-76). Cambridge, MA: The MIT Press.

Hayes, B. (In press). Gradient well-formedness in Optimality Theory. In Dekkers et al. (eds).

Hewitt, M. S. and Crowhurst, M. J. (1996). Conjunctive constraints and templates in Optimality Theory. NELS 26. To appear.

Hjelmslev, L. (1953). Prolegomena to a Theory of Language. Madison: University of Wisconsin Press. (Original work published 1943.)

Hudson, R. (1977). The power of morphological rules. Lingua 42, 73-89.

Hudson, R. (1997). I aren't and multiple inheritance. London: University College, London Department of Phonetics and Linguistics MS.

Hughes, G. A. and P. Trudgill. (1979). English Accents and Dialects: An Introduction to Social and Regional Varieties of English. Longdon: Edward Arnold.

Ihalainen, O. (1991). On grammatical diffusion in Somerset folk speech. In Trudgill and Chambers (eds.), (pp. 104-19). 
Ingria, R. J. P. (1990). The limits of unification. In Proceedings of the 28th Annual Meeting of the Association for Computational Linguistics (pp. 194204).

Jackendoff, R. (1972). Semantic Interpretation in Generative Grammar. Cambridge, MA: The MIT Press.

Jakobson, R. (1984). Structure of the Russian verb. In L. R. Waugh and M. Halle (eds), Roman Jakobson. Russian and Slavic Grammar. Studies 19311981 (pp. 1-14). Berlin: Mouton Publishers. (Original work published 1932.)

Johnson, M. (Forthcoming). Comments on the paper by Bresnan. Paper presented at Annual CUNY Conference on Human Sentence Processing, Special Session on the Lexical Basis of Syntactic Processing: Formal and Computational Issues, Rutgers University, March 20, 1998.

Johnson, M. and Bayer, S. (1995). Features and agreement in lambek categorial grammar. In G. V. Morrill and R. T. Oehrle (eds), Formal Grammar. Proceedings of the Conference of the European Summer School in Logic, Language and Information, Barcelona, 1995 (pp. 123-37).

Karttunen, L. (1984). Features and values. Proceedings of Coling 84, 28-33. Morristown, NJ: Association for Computational Linguistics.

Kiparsky, P. 1973. Elsewhere in phonology. In S. Anderson and P. Kiparsky (eds), A Festschrift for Morris Halle (pp. 93-106). New York: Holt, Rinehart, and Winston.

Kim, J.-B. and Sag, I. (1996). French and English negation: a lexicalist alternative to head movement. Stanford, CA: Stanford University Department of Linguistics MS.

King, T. H. (1995). Configuring Topic and Focus in Russian. Stanford: CSLI Publications.

Klima, E. S. (1964). Negation in English. In J. A. Fodor and J. J. Katz (eds), The Structure of Language (pp. 246-323). Englewood Cliffs, N.Y: Prentice-Hall.

Kroeger, P. (1993). Phrase Structure and Grammatical Relations in Tagalog. Stanford: CSLI Publications.

Langendoen, D. T. (1970). Essentials of English Grammar. NY: Holt, Rinehart, and Winston. 
Lee, H. (1998). Discourse competing with syntax: prominence and "misplaced" que in child French. Paper presented at the workshop Is Syntax Different? Common cognitive structures for syntax and phonology in Optimality Theory, CSLI, Stanford University, December 12-13, 1998.

Legendre, G., Smolensky, P., and Wilson, C. (1998) When is less more? Faithfulness and minimal links in wh-chains. In Barbosa et al. (eds), (pp. 249-89).

Legendre, G., Grimshaw, J., and Vikner, S. (eds), (Forthcoming). Optimality Theoretic Syntax. Cambridge, MA: The MIT Press.

Lumsden, J. S. (1992). Underspecification in grammatical and natural gender. Linguistic Inquiry 23, 469-86.

Matthews, P. H. 1972. Inflectional Morphology. Cambridge: Cambridge University Press.

Maxwell, J. T. and Kaplan, R. M. (1995). A method for disjunctive constraint satisfaction. In Dalrymple, et al. (eds.), (pp. 381-401).

Miller, J. (1993). The grammar of Scottish English. In Milroy and Milroy (eds.), (pp. 99-138).

Milroy, J. and Milroy, L. (eds), (1993). Real English. The Grammar of English Dialects in the British Isles. London: Longman.

Morimoto, Y. (1998). Dative objects in Japanese -sa nominalization. In Butt and King (eds).

Nordlinger, R. (1998) Constructive Case. Evidence from Australian Languages. Stanford: CSLI Publications.

Orton, H. and Dieth, E. (eds), (1962-). Survey of English Dialects. Leeds: Leeds, published for the University of Leeds by E. J. Arnold.

Palmer, H. E. and Blandford, F. G. (1969). A Grammar of Spoken English. Third edition, revised and rewritten by Roger Kingdon. Cambridge: W. Heffer and Sons Ltd.

Payne, J. R. (1985). Negation. In T. Shopen (ed), Language Typology and Syntactic Description. Vol. I: Clause Structure (pp. 197-242). Cambridge: Cambridge University Press.

Pollard, C. and Sag, I. A. (1987). Information-Based Syntax and Semantics. Vol. 1: Fundamentals. Stanford: CSLI Publications. 
Poser, W. J. (1992). Blocking of phrasal constructions by lexical items. In I. A. Sag and A. Szabolcsi (eds), Lexical Matters (pp. 111-30). Stanford: CSLI Publications.

Prince, A. and Smolensky, P. (1993). Optimality Theory: constraint interaction in generative grammar. RuCCS Technical Report \#2. Piscateway, NJ: Rutgers University Center for Cognitive Science.

Pullum, G. K. and Zwicky, A. M. (1997). Licensing of prosodic features by syntactic rules: the key to auxiliary reduction. Paper presented at the 1997 Linguistic Society of America meeting, Chicago.

Sadler, L. (1997). Clitics and the Structure-Function Mapping. In Butt and King (eds).

Sells, P. (1996). Case, categories, and projection in Korean and Japanese. In H.-D. Ahn, M.-Y. Kang, Y.-S. Kim, and S. Lee (eds), Morphosyntax in Generative Grammar (Proceedings of 1996 Seoul International Conference on Generative Grammar) (pp. 47-62). Seoul: The Korean Generative Grammar Circle, Hankwuk Publishing Co.

Sells, P. (1997a). Optimality and Economy of Expression in Japanese and Korean. To appear in the Proceedings of the \%th Japanese/Korean Conference. Stanford: CSLI Publications.

Sells, P. (1997b). Positional constraints and faithfulness in morphology. To appear in Susumo Kuno et al. (eds), Harvard Studies in Korean Linguistics 7. Cambridge: Harvard University.

Sells, P. (1998a). Scandinavian clause structure and object shift. In Butt and King (eds).

Sells, P. (1998b). Syntactic positioning as alignment: object shift in Swedish. Paper presented at the workshop Is Syntax Different? Common cognitive structures for syntax and phonology in Optimality Theory, CSLI, Stanford University, December 12-13, 1998.

Shieber, S. M. (1986). An Introduction to Unification-Based Approaches to Grammar. Stanford: CSLI Publications.

Smith, J. (1997) Noun faithfulness: on the privileged behavior of nouns in phonology. On-line, Rutgers University: Rutgers Optimality Archive, http://ruccs.rutgers.edu/roa.html. 
Smolensky, P. (1996a). The initial state and 'richness of the base' in Optimality Theory. Technical Report JHU-CogSci-96-4, Department of Cognitive Science, Johns Hopkins University.

Smolensky, P. (1996b). Generalizing optimization in OT: a competence theory of grammar 'use'. Paper presented at the Workshop on Optimality Theory and Cognition, Center for the Study of Language and Information, Stanford University, December 6, 1996.

Steriade, D. (1995). Underspecification and markedness. In J. Goldsmith (ed), Handbook of Phonological Theory (pp. 114-74). Oxford: Blackwell.

Stockwell, R. P., Schachter, P., and Partee, B. H.. (1973). The Major Syntactic Structures of English. New York: Holt, Rinehart and Winston.

Tesar, B. and Smolensky, P. (1996). The learnability of Optimality Theory: an algorithm and some basic complexity results. Technical Report, Cognitive Science Department, Johns Hopkins University, Baltimore, Maryland and Rutgers Center for Cognitive Science, Rutgers University, New Brunswick, New Jersey.

Trudgill, P. and Chambers, J. K. (eds), (1991). Dialects of English. Studies in Grammatical Variation. London: Longman.

Vijay-Shanker, K., and Joshi, Aravind K. (1990). Unification based tree adjoining grammars. In J. Wedekind (ed.), Unification-based Grammars (pp. xxx-xxx). Cambridge, MA: The MIT Press.

Vincent, N. (1998a). Competition and correspondence in syntactic change: null arguments in Latin and Romance. Paper delivered at the 5th Diachronic Generative Syntax Conference (DIGS5), University of York, May 30-June $1,1998$.

Vincent, N. (1998b). The development of the Romance auxiliary split: an OT approach. Paper presented at the workshop Is Syntax Different? Common cognitive structures for syntax and phonology in Optimality Theory, CSLI, Stanford University, December 12-13, 1998.

Vincent, N. and Börjars, K. (1996). Suppletion and syntactic theory. In Butt and King (eds), (pp. 448-62).

Unseth, P. (1994). Verbal negation in Majang. Paper presented at the $25^{\text {th }}$ Annual Conference on African Linguistics, 1994, Rutgers University. 
Urbanczyk, L. (1995) Double reduplications in parallel. In Beckman et al. (eds), (pp. 499-531).

Zwicky, A. M. and Pullum, G. K. (1983). Cliticization vs. inflection: English n't. Language 59, 502-13. 